\title{
Embedding power system's reliability within a long-term Energy System Optimization Model: Linking high renewable energy integration and future grid stability for France by 2050
}

\author{
Gondia Sokhna SECK $^{\mathrm{a}, *}$, Vincent KRAKOWSKI ${ }^{\mathrm{b}}$, Edi ASSOUMOU ${ }^{\mathrm{b}}$, Nadia MAÏZI ${ }^{\mathrm{b}}$, \\ Vincent MAZAURIC ${ }^{\text {b,c }}$ \\ July, $9^{\text {th }} 2019$
}

\begin{abstract}
The aim of this article is to take into account short-term power grid operation conditions in long-term prospective analysis in the case of France. It is the first time that the integration of system adequacy and transient stability has been achieved in prospective studies for an electro intensive country, following studies conducted on Reunion Island. The methodology relies on a quantitative assessment of the French power sector's reliability through an endogenous definition of a reliability indicator related to kinetic reserves into an Energy System Optimization Model (ESOM), TIMES-FR model. The result gives an overview of how the stability of the grid is maintained with an increasing share of renewables using additional back-up and flexible options. We observe that it is technically possible to achieve around 65\% of Variable Renewable Energy sources (VREs) in the installed capacity without impairing the reliability of the system. In more detail, the maximum VRE in total hourly power production that complies with the reliability constraint was assessed as around $84 \%$ in the 100 EnR scenario. However, in order to guarantee this system reliability, the cumulated new installed capacity, in a scenario with 100\% renewable energy sources (RES) in the power mix, would represent the double of the Business-As-Usual (BAU) scenario over the period 2013-2050. Therefore, major upstream planning would be needed, and that more flexible options i.e. demand-response, storage technologies and interconnections or substitute or additional plants should be considered to satisfy the reliability constraint at any time by providing extra inertia to the system. This modelling exercise shows the importance of power exchanges with neighbours with higher share of RE in the power production.
\end{abstract}

Keywords: Renewable energy sources; Grid reliability; Transient stability; System adequacy; Power sector; TIMES model

a. IFP Énergies Nouvelles, 1-4 av. de Bois Préau, F-92852 Rueil-Malmaison, France.

b. Mines ParisTech, PSL Research University, Centre for Applied Mathematics, 1 rue Claude Daunesse, 06904 Sophia Antipolis, France

c. Schneider Electric, Corporate Research, 38TEC Building, 38050 Grenoble, France.

* Corresponding author. Tel.: +33147525012

E-mail address: gondia-sokhna.seck@ifpen.fr 


\section{Introduction}

Unlike other energy sources that are concentrated in a limited number of countries, renewable energy sources (RES) exist in a wide geographical area. Thus, increasing integration of the latter into electricity generation could help tackle resource scarcity, energy dependency and environmental issues. Transition of the energy system towards sustainable development that reconciles greenhouse gas (GHG) reduction targets with increasing competitiveness and supply security is being explored in many long-term energy roadmaps [1][2][3][4][5]. This sustainable development would meet the needs of the present without compromising the ability of future generations to meet their own needs [6]. The 2015 United Nations Climate Conference in Paris was a watershed moment for renewable energy, since operation of RES is GHG emission-free (with a specific constraint on biomass management).

RES accounted for $18.2 \%$ of total final energy consumption in 2016, more than half of which comes from modern renewables (with biomass and hydropower accounting for the largest share) [7], and about $24.5 \%$ of power generation, more than two thirds of which comes from hydropower (Fig. 1(a)). In Europe this figure is even higher, with RES accounting for about $34 \%$ of electricity production (Fig. 1(b)) [8].

(a)

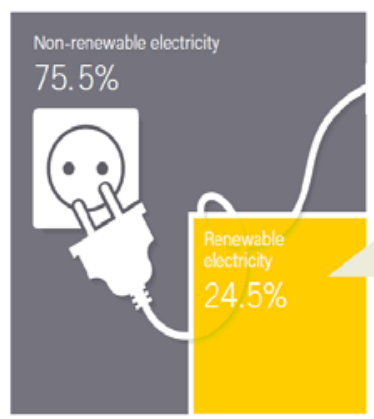

(b)
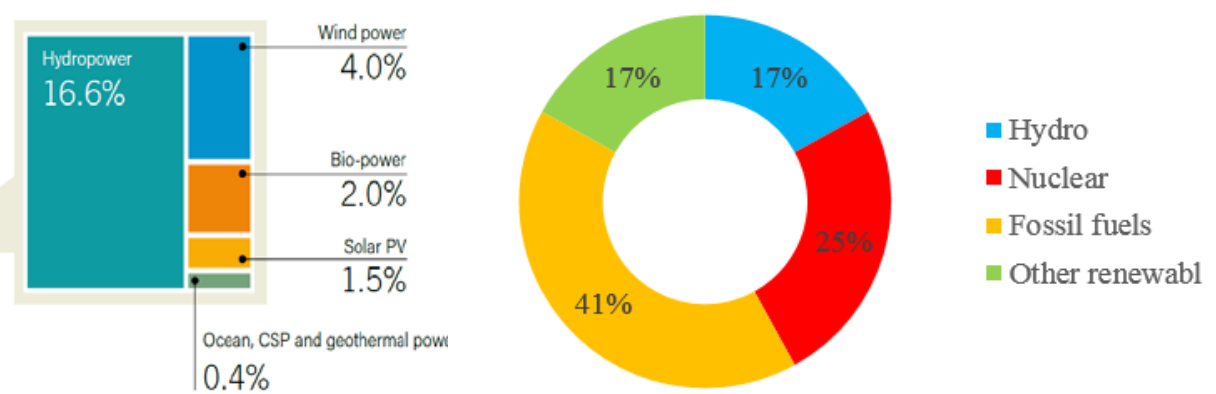

Source: Renewables 2017 global status report - Source: ENTSOE- Electricity in Europe REN21 2016

\section{Fig. 1 : (a) Estimated Renewable Energy Share of Global Electricity Production in 2016. (b) Overall ENTSO-E energy net generation in 2016.}

France is clearly late in terms of renewable energy share despite its huge hydropower production (around 12.1\%) (Fig. 2). Nevertheless, the country's renewable energy targets for 2020 are $23 \%$ in final energy consumption and 27\% in power production. Recent, more constrained targets have also been decided for 2030 at respectively 32\% and 40\% of the final energy consumption. If France wants to achieve its own targets, it must undertake a considerable power system evolution. We address this evolution from a prospective point of 
view, i.e. an exploration of the long-term through contrasted scenarios to question the evolution development of the French power system with RES penetration

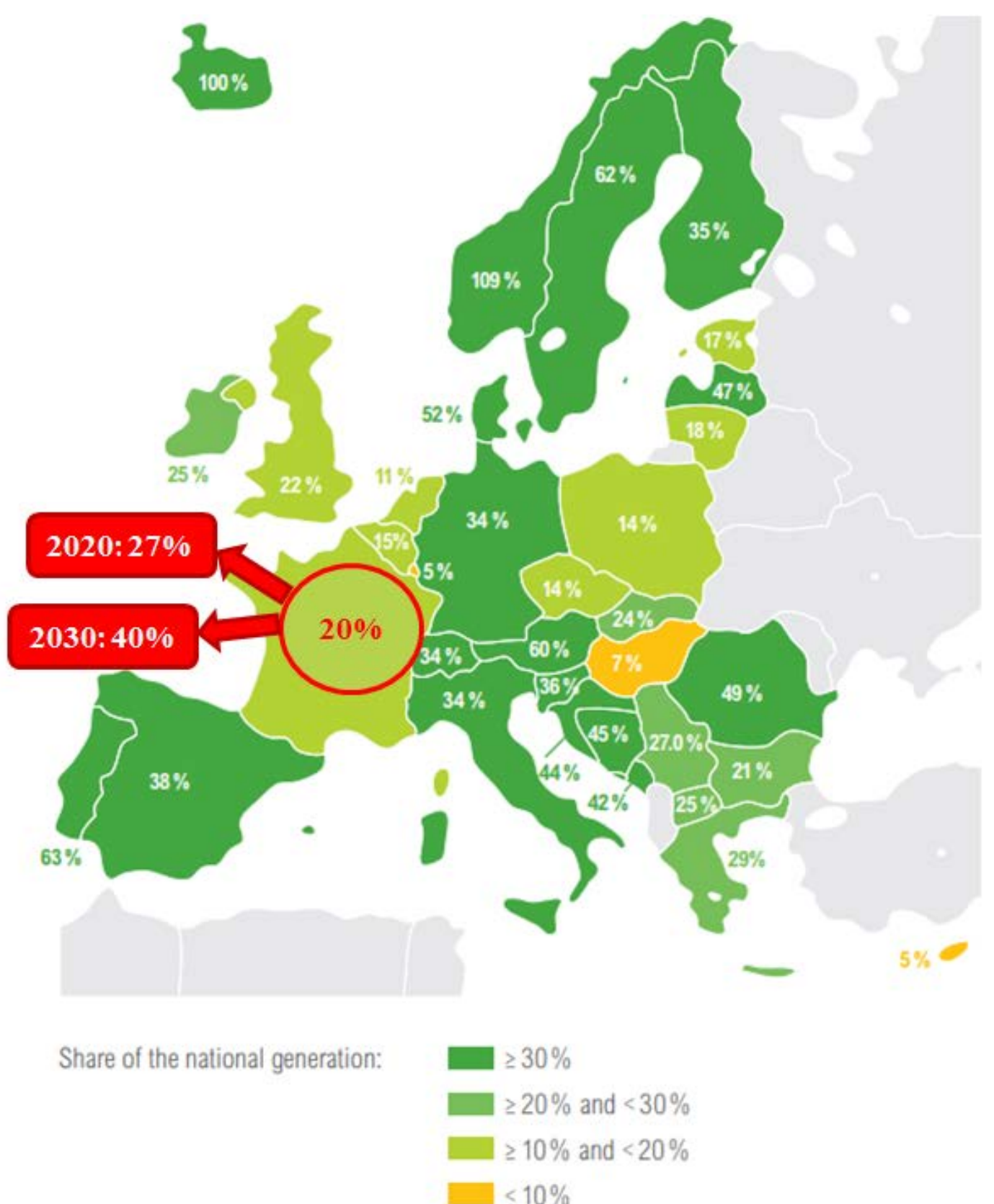

Fig. 2: Share of consumption covered by renewable generation in 2016 per country in the ENTSOE area (Focus on France with its own 2020 and 2030 RES targets).

However, RES are dominated by variable renewable energy (VRE) (solar, wind and wave power). Due to their high variability and lower predictability, high levels of VRE could jeopardize the reliability of the power system.

In France, 72.5\% of electricity supply comes from nuclear power plants in 2016, which makes the French electricity generation structure unique. Moreover, nuclear power replacement will 
be the main lever in the future, as the recent energy debate in France has shown. One of the main questions is how it might be possible to perform as well as nuclear power in terms of emissions and grid reliability using more renewable energy sources in the future electricity generation mix, given that RES participate little in power system inertia. This issue must be assessed in a context featuring numerous environmental and technical constraints.

Why is it a modelling issue? The reason that modelling is pertinent here is because power system modelling poses challenges that are specific to the sector. These challenges include ensuring a permanent supply-demand balance despite the complexity of infrastructures. In other words, a suitable assessment of system adequacy is mandatory, featuring the integration of large amounts of renewable energy sources, the completion of the internal electricity market, as well as new storage technologies, demand side response and evolving policies (ENTSO-E) ${ }^{1}$. In addition, as shown in Fig. 3 by the red dotted circle, the functioning of the power sector involves short time scales from fractions of seconds to hours. Since contingencies are inevitable at this scale, transient stability in power systems is also required. This refers to the ability of a synchronous power system to return to a stable condition and maintain its synchronism following a relatively large disturbance arising from very general situations.

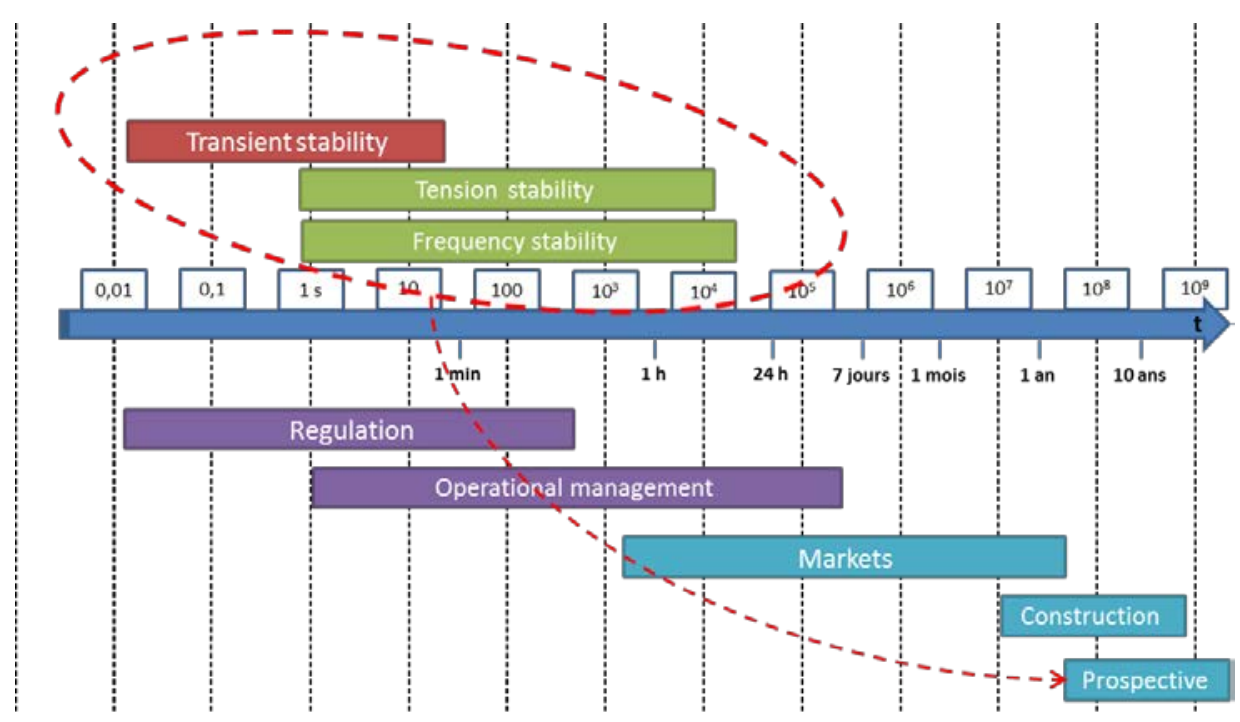

Fig. 3 : Reconciliation of the short-term dynamics of power system management with long-term prospective analysis.

The methodology developed here over more than a decade focuses on integrating system adequacy and transient stability into prospective analyses, which is crucial to an appropriate dimensioning of the electrical system. After an initial study on Reunion Island [9], for the first

\footnotetext{
${ }^{1}$ https://www.entsoe.eu/about-entso-e/system-development/system-adequacy-and-market-modeling/adequacymethodology/Pages/default.aspx
} 
time this research is now applying the same methodology to a power-intensive country like France.

In this paper, we focus on the first phenomenon, which is related to how the system reacts to face a fluctuation. We take the example of an increase in the load (loss of a power plant or a sudden increase in demand) (Fig. 4) assuming that synchronism is maintained [9]. The variations in frequency are the reflect of the imbalances. When production decreases or consumption increases, the frequency decreases. Moreover, the frequency is related to the rotation speed of the machines. A decrease in the frequency means a decrease in the rotation speeds, which implies a decrease in the kinetic energy embodied in the rotating machines. This kinetic energy (red circle in Fig. 4) constitutes the inertia of the power system to face a sudden disturbance before the primary, secondary and tertiary regulations are triggered (more details on this in [10]). The latter help the system to stabilize frequency disruptions.

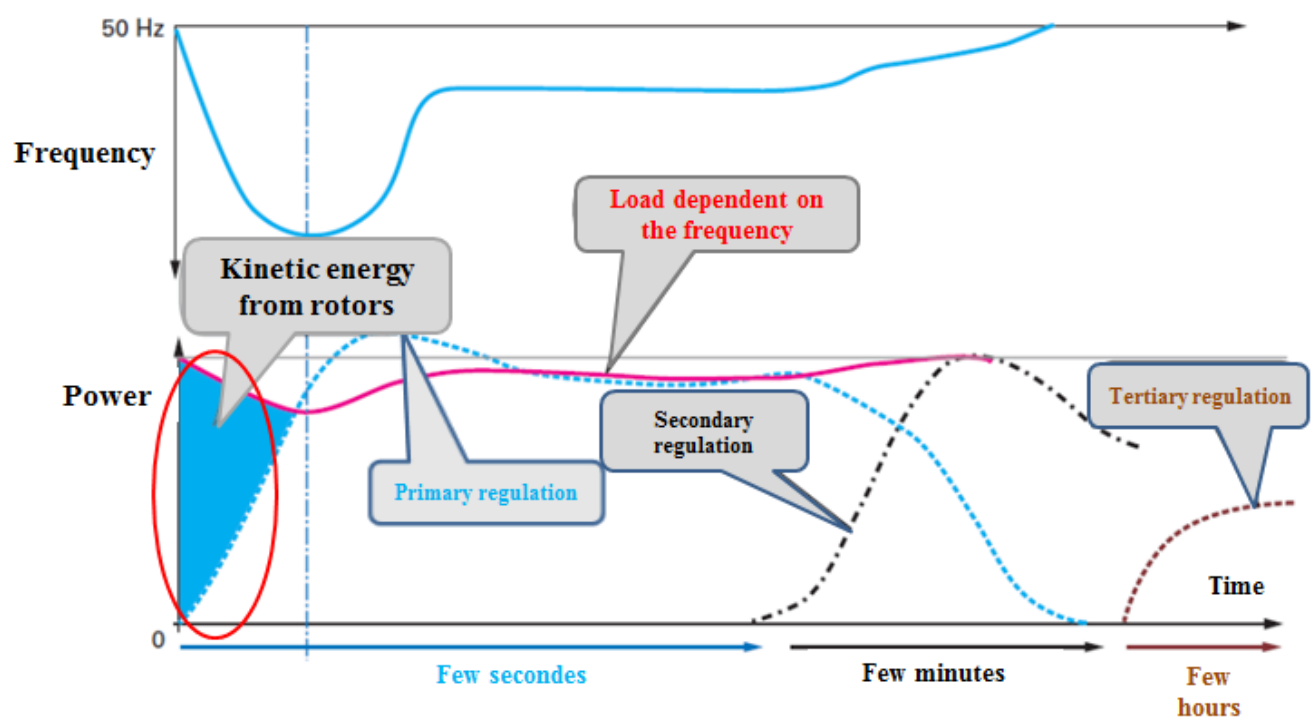

Fig. 4 : The functioning of the power grid facing a disturbance [11].

We implicitly consider that the power system should be able to deal with hazards without relying on VREs, whose production is not completely predictable, cannot be adjusted to match demand, and above all makes a limited participation to system services, like these kinetic reserves. It is essential to be able to represent this inertia of the system in our model.

Many papers related to the integration of an increasing share of RES in power system using long term energy planning have been done during the last decade. According to system operators, current limited penetration rate of RES, specially the VREs, can be integrated reliably, profitably and affordably but large uncertainties remain about the impact of their widespread diffusion on the power system reliability once the inherent flexibility that was built in the grid decades ago is reached [12]. Indeed, Collins et al. used a soft-linked between 
PRIMES $^{2}$ and PLEXOS ${ }^{3}$ to quantify impacts of increased renewable electricity generation on the EU's power system flexibility [13][14]. Antenucci et al. investigated as well the European energy transition by analysing to what extent an energy system planning model guarantees the security of supply using a multi model methodological framework [15]. They combined the long-term perspective of the European Model for Power system Investment with Renewable Energy (EMPIRE model) [16][17] with a detailed network operation analysis via the Nexus Security Model (NSM). However, both of them needed a multi model methodological framework in order to better capture flexibility aspect of the power sector which is not sufficiently embedded in long-term energy models, commonly used in literature for long term energy planning and energy policy. As said by Heylen et al., future work should focus on further developing risk-based indicators to guide the decision-making process of power system reliability management towards secure and cost-effective decisions [18], and by extension their implementation in any long-term energy model. Thus, by considering reliability indicator in a long term energy model, this paper contribute filling the gap identified in the literature on energy system optimization models. It will allow avoiding sub optimal planning with misleading signals regarding the cost and difficulty of achieving carbon reduction targets, thus to capture within only one stand-alone long-term energy planning model the operational integration of renewable technologies for the power sector.

In our article, one indicator related to kinetic reserves, which is developed based on a thermodynamic description of power systems [19], represents the power system's ability to keep working following a disturbance. This kinetic reserve comes from the rotation of machines connected to the grid and compensates for unbalanced power exchanges before the start-up of the primary control [20]. This approach has been used in a long-term planning model (LTPM) in the case of Reunion Island [21][22] as well as for France in multi model methodology framework via post-treatment of a long-term model results [23]. These previous results for France showed that $100 \%$ renewable energy scenarios could lead to a decrease of two-thirds of kinetic reserves. In this study, the main goal is to "endogenize" the kinetic indicator in the TIMES model for mainland France to evaluate whether an additional reliability constraint would affect the solution for high RES integration in the energy mix. Different RES ambitions will be assessed during the modelling analyses. Unlike previous work on France, this "endogenization" of the indicator will allow us to directly obtain from the model the different technology pathways to apply a reliability constraint on the power grid.

\footnotetext{
${ }^{2}$ Apartial equilibrium model with a rich technology description that projects energy demand and technology deployment for the period between today and 2050

${ }^{3}$ Plexos is a model which is used to optimize the dispatch renewable generation and pumped hydro storage
} 
To do so, the linear formulation is changed to a "lumpy" investment option in order to be able to evaluate the participation of each power plant to the kinetic reserve from the assessment of the inertia embodied in their rotating masses. The method for reliability is similar to earlier experiments for Reunion Island, which showed that 100\% RES with appropriate dispatch of local sugar cane does not jeopardize kinetic reserves [24].

In this report, the question is to observe and assess the changes in terms of power system stability in a new energy model paradigm with less nuclear power based on the new French framework law on energy. Thus, instead of only presenting how reliability evolves according to the share of RES in the power production, our model will allow us to answer the following questions:

- How does the kinetic indicator evolve without/under a reliability constraint?

- What are the possible technology changes (installation of controllable means of production, storage capacity, increased trade with neighbouring countries, or demandresponse options) necessary to prevent the reliability of the power system from decreasing?

- What is the evolution of the VRE share in the installed capacity, or the maximum VRE share in the demanded? apparent power achieved during each year of the study for all RES ambitions?

- How does the hourly production mix evolve for a typical constrained week or weekend day according to the season with the RES ambition?

The rest of the paper is organized as follows : Section 2 describes the methodology, the overall structure and main assumptions of the TIMES-FR model for mainland France, followed by the description of the equation for the reliability constraint. The ; Section 3 presents the different analyses of the modelling results and finally Section 4 summarizes our findings and research perspectives

\section{Methodology}

\subsection{The reference energy system}

TIMES-FR (The Integrated MARKAL-EFOM System) is is a version of the TIMES model generator (formalism) developed at the Center for Applied Mathematics of Mines ParisTech. It is a "bottom-up" techno-economic model with a technology-rich basis for estimating energy dynamics over a long-term, multi-period time horizon [25][26][27]. This technology rich modelling paradigm provide insights to decision makers regarding energy systems in order to determine what technologies are competitive, marginal or uncompetitive in each market 
according to dynamic economic cost-benefit analyses. TIMES has been developed, maintained and promoted through ETSAP (Energy Technology Systems Analysis Program) which is one of the longest running Technology Collaboration Programme of the International Energy Agency (IEA). TIMES models encompass all the steps from primary resources to the demand-side via the chain of processes that transform, transport, distribute and convert energy into the supply of energy services demanded by energy consumers. The demand-side is structured by sector and exogenous import and export are also considered in the reference energy system (RES). This reference energy system is a network of processes linked by their inputs and outputs, all constraints, technical, economic and policy based parameters, to clearly analyse the relevance of optimal technology paths according to environmental and/or energy solicitations (Fig. 5).

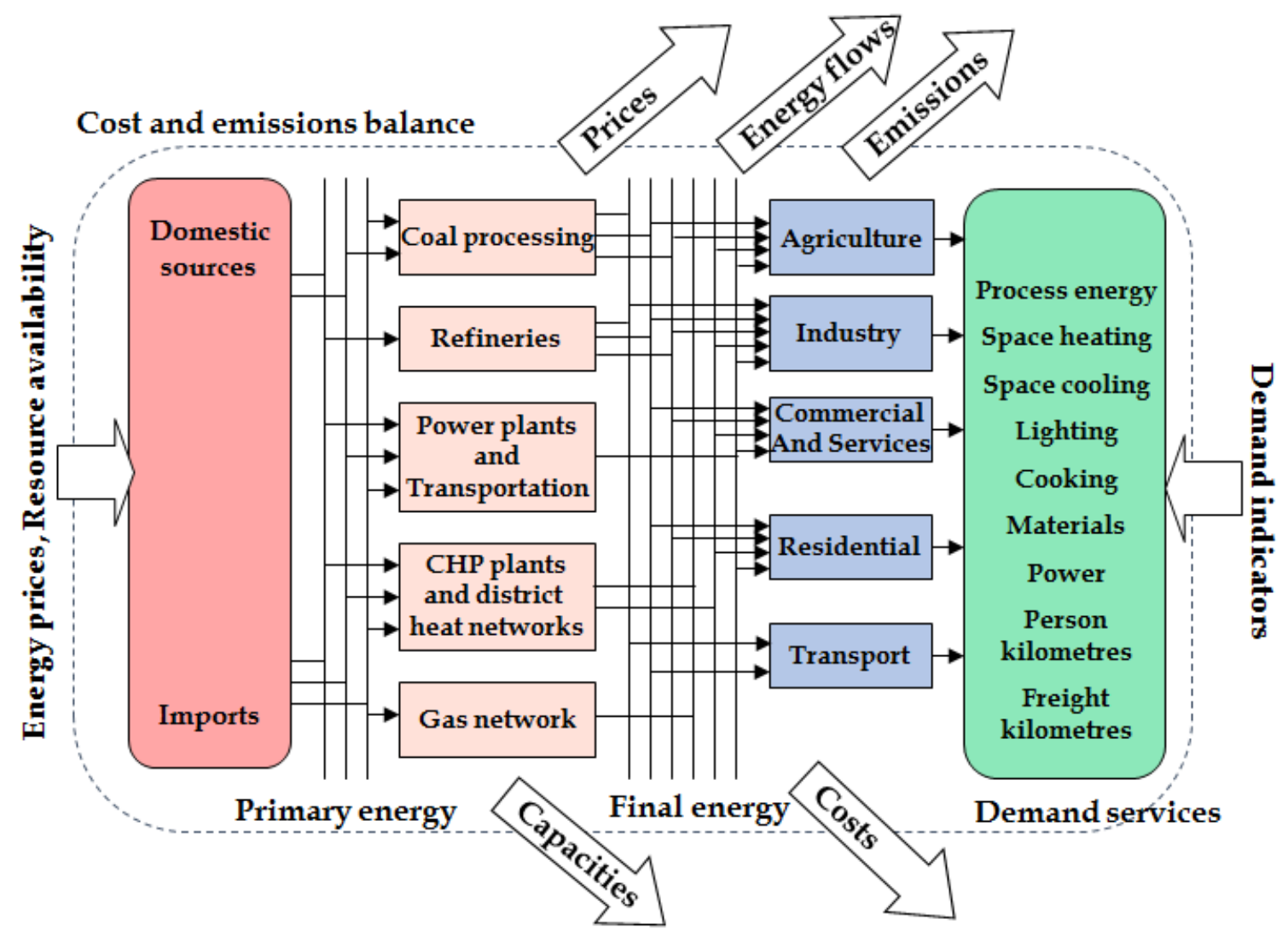

Fig. 5 : Simplified representation of the Reference Energy System (RES) [28]

It is a partial equilibrium model belonging to the MARKAL family, which means it provides no feedback on sectorial changes in other economies and the suppliers of energy produce the quantity to meet the exogenous demand services considered. However, in most developed economies like France, these impacts are of secondary importance [29]. A more detailed reference energy system with neighbouring countries is depicted in Fig. 6. 


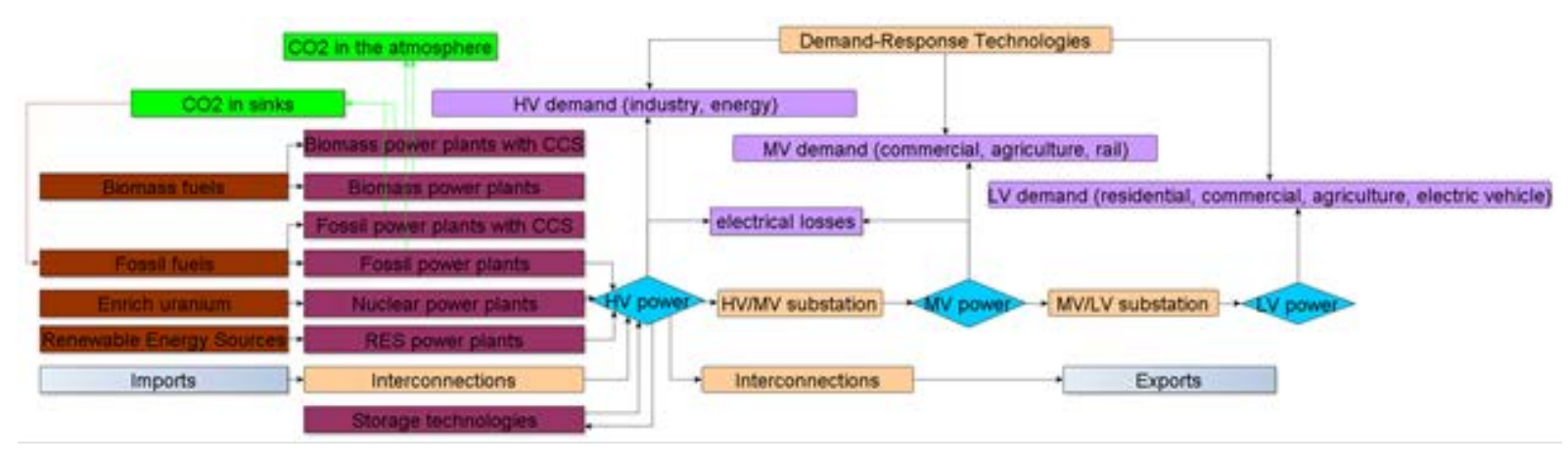

Fig. 6 : Detailed schematic description of the reference energy system [24]

The objective function is the criterion that is minimized by the TIMES model under constraint. It represents the total discounted cost of the system over the selected planning horizon (Eq. (1)). A detailed description of the objective function equations is provided in Part II, section 6.2 of the TIMES documentation [26]. We limit our description to giving general indications on the annual cost elements contained in the objective function:

- Investment costs incurred for processes;

- Fixed and variable annual costs,

- Costs incurred for exogenous imports and revenues from exogenous exports;

- Delivery costs for required commodities consumed by processes;

- Taxes and subsidies associated with commodity flows and process activities or investments;

$$
N P V=\sum_{r=1}^{R} \sum_{y \in Y E A R S}\left(1+d_{r, y}\right)^{R E F Y R-y} * \operatorname{ANNCOST}(r, y)
$$

$\boldsymbol{N P V}$ is the net present value of the total cost for all regions (the TIMES objective function);

$\operatorname{ANNCOST}(\boldsymbol{r}, \boldsymbol{y})$ is the total annual cost in region $r$ and year $y$ (more details in section 6.2 of PART II [26])

$\boldsymbol{d}_{r, \boldsymbol{y}}$ is the general discount rate;

$\boldsymbol{R E F Y R}$ is the reference year for discounting;

YEARS is the set of years for which there are costs, including all years in the horizon, plus past years (before the initial period) if costs have been defined for past investments, plus a number of years after EOH where some investment and dismantling costs are still being incurred, as well as Salvage Value; and

$\boldsymbol{R}$ is the region which is France in our TIMES-FR. 
The components of the cost of the system are expressed in each year of the studied horizon (and even for some years beyond the horizon), unlike the constraints and variables, which are related to the period. For every specified period, it maximizes the total net surplus (suppliers and consumers) by respecting the defined constraints regarding the availability of resources, capacity transfer, etc. This choice allows a more realistic representation of payment flows performed in the energy system [30].

The model was developed to analyse and assess the possible consequences of various energy, environmental and legislative orientations with an explicit, detailed technology and representation of an energy carrier. It is suitable for assessing long-term investment decisions in a complex environment.

Contrary to previous works on the same topic for France based on a continuous mode [24][31][32], we introduced a lumpy investment option, which consists in a discretization of the new processes (discrete mode). The accuracy of certain investment decisions could be problematic in some cases due to the linearity property of the TIMES model. For instance, the size of an electricity generation plant proposed by the model would have to conform to an implementable minimum size (it would make no sense to decide to construct a $50 \mathrm{MW}$ nuclear plant). Thus, the lumpy investment option available in TIMES insures that investment in technology k is equal to a finite number $N$ of a pre-determined size: $0, S_{1}(t), S_{2}(t), \ldots, S_{N}(t)$. As implied by the notation, these discrete sizes may be different at different time periods. Note that by choosing the $\boldsymbol{N}$ sizes as the successive multiples of a fixed number $\mathrm{S}$, it is possible to invest (perhaps many times) in a technology with a fixed standard size [26]. For such a scope with small-scale renewable power plants, the granularity of some investments may have to be taken into account to improve the robustness of the power sector's modeling even though this is time-consuming (3,693 new processes in discrete mode in comparison with 204 new processes in continuous mode).

\subsection{Main assumptions}

In this section, the main assumptions of this model are listed below (for more details, refer to [24]). The first group consists in modelling settings. The second one describes the implementation of flexibility options while the third one provides the technical adaptation of the program to take advantage of reasonable computing costs and the different scenarios considered in this paper: 


\subsubsection{Modelling settings}

- One of our assumptions is the choice of the discount rate for the model. In this case, we consider the public discount rate (state vision), which reflects the objective of socioeconomic profitability expressing the general interest by taking collective preferences into account on the spread of cash flows over time and macroeconomic factors [33]. It sets the limit that the community is willing to accept by arbitrating between current and future choices. In a report published in January 2005 a task force chaired by D. Lebègue proposed a downward revision of this rate, from $8 \%$ to $4 \%$, with a gradual decrease in assessments that focus on the very long term [34][35]. Choices related to climate change or decisions on the management of radioactive waste typically fall within order of the century or more due to the long duration of some projects. A high discount does not mean considering the effects of our actions over time horizons as being far apart, but rather imagining that these effects grow at a similar rate. This leads to the choice of a gradual evolution of the discount rate: a value of $4 \%$ as constant for a time horizon of around 30 years, then decreasing down to $2 \%$. Thus, an assumption of $4 \%$ has been considered and kept constant over our modelling time horizon up to 2050.

- The horizon of study is 2013-2050 divided into 9 time periods of 84 time-slices each (Fig. 7). A hypothetic week called Cweek (constrained week) has been added to the model to take into account the inter-annual variability of the variable renewable energies. It represents a potential winter week with low solar and wind production and zero imports.

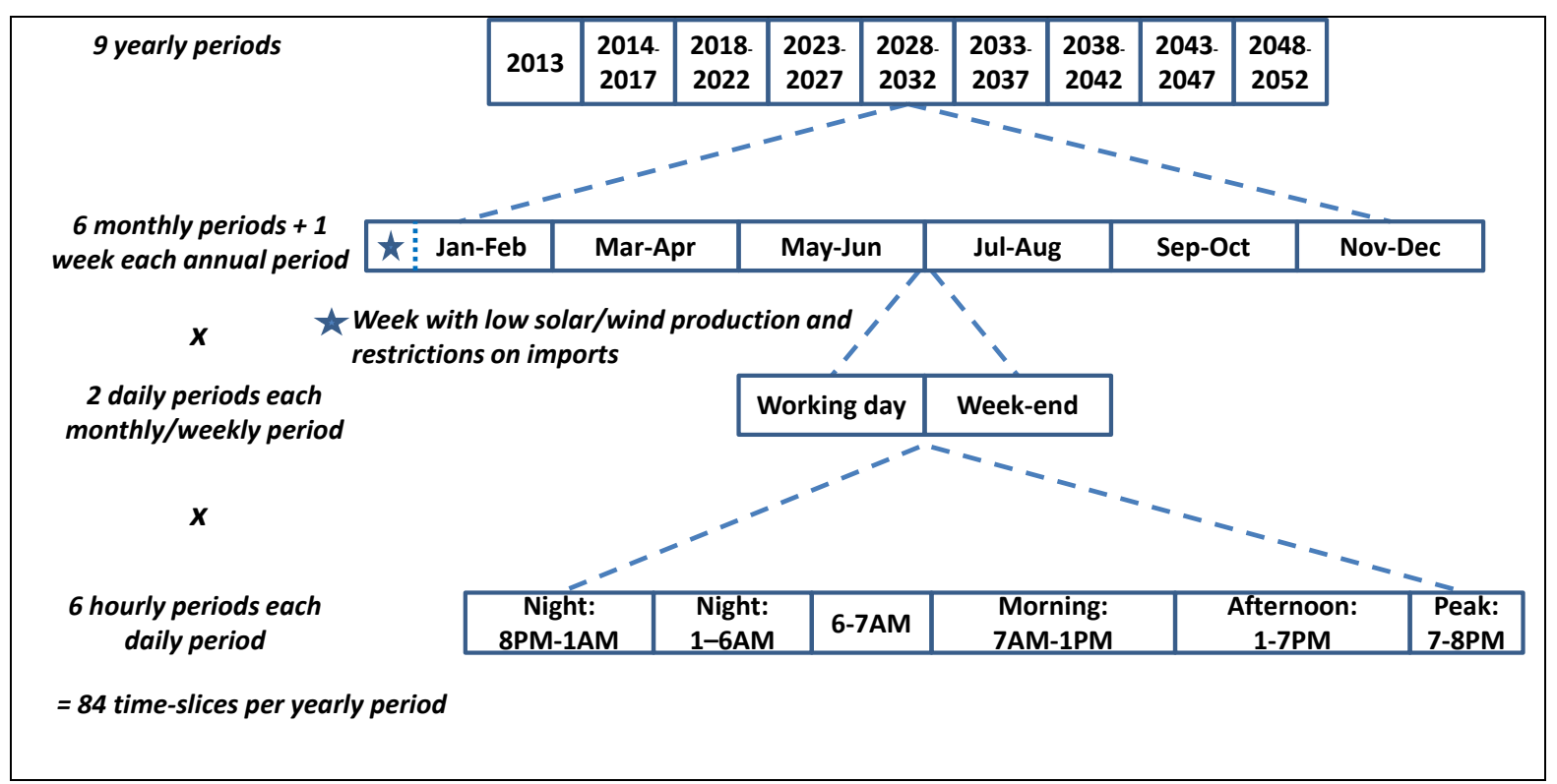

Fig. 7 : Time horizon disaggregation 
- According to ADEME data [36], we implemented a certain limit on maximal installation of new capacity in 2030 and 2050 for several technologies such as RES and storage technologies.

\subsubsection{Implementation of flexibility options}

We integrated three options for flexibility into the model in the aim of flattening the load curve:

- Demand-Response technologies (DR) (load-shifting) follow the methodology developed in [37]. We distinguished two types: Hourly DR that enables long-term postponement and Sub-hourly DR for short-term postponement. The former represents devices that can be deferred from one time slice to another in the same day without modifying final daily consumption (water heaters, clothes washing and dishwashing machines, driers, etc.). An assumption of $10 \%$ of final consumption from the residential, services, industry sectors and 50\% from passenger car transport (due to EV/PHV) could be reached in 2050 and has been considered in the model (the total load-shifting is now estimated at around 5\% [38]). The latter encompasses devices that could be stopped for less than an hour, so smaller than our considered time-slice (heating, cooling, ventilation, etc.). In this case, we assumed $10 \%$ of the final consumption only in the residential and services sectors.

- Storage technologies include pumped hydroelectric storage (PHS), advanced adiabatic compressed air energy storage (AA-CAES), dynamic storage (batteries, flywheels) and a technology called "other storage”, which represents other forms of storage such as hydrogen storage and thermal energy storage. However, only PHS, AA-CAES and "other storage" can be used as energy, which means that they can be loaded in a time slice with a less taut supply-demand balance and deliver power in another one. This is not the case for the other technologies that can deliver power for less than 15s, like batteries (NaS, Li-ion, PbA) or flywheels, because of the time-resolution of our model. However, these storage devices supply power to the system in order to maintain the frequency (see Eq. (2) below).

- The new interconnections.

\subsubsection{Technical adaptation of the modelling}

The kinetic indicator, which is expressed in seconds, is introduced for quantifying a system's kinetic inertia [9][31] has been implemented in the TIMES model code. This indicator represents the duration during which the stock of kinetic reserve runs out completely to help 
recovering the steady state conditions if the power generation is suddenly disconnected, or, conversely, the final consumption rushes to its peak $\mathrm{P}_{\text {peak }}$ :

$$
H_{\mathrm{kin}}=\frac{E_{\mathrm{kin}}}{\max \left(S, P_{\text {peak }}-S\right)-Q_{\mathrm{stg}}}
$$

where:

- $\mathrm{S}$ is the apparent power supplied by the generators just before the disturbance,

- $\mathrm{Q}_{s}$ denotes the "on-grid” storage technologies (subscripted by s) available to dynamically sustain the frequency under a delayed time $\tau_{\mathrm{s}}$ (typically lower than $30 \mathrm{~s}$ ) [39] :

$$
Q_{\text {stg }}=\sum_{s} Q_{s} \mathbf{1}_{t>\tau_{s}}
$$

The indicator $\mathrm{H}_{\text {kin }}$ quantifies the kinetic energy stored compared to the supplied apparent power minus the dynamic storage compensation. More the indicator is bigger; more the system is able to maintain the balance after a perturbation. To ensure a continuum with the primary regulation which typically operates within 15-30 seconds, it is mandatory to enforce to the indicator $\mathrm{H}_{\text {kin }}$ be greater than a certain value $\mathrm{H}_{\text {critical }}$ (fixed in our study at 30 seconds) to stabilize frequency disruptions:

$$
H_{\text {kin }} \geq H_{\text {critical }}=30 s
$$

Thus our model shows the possible technology paths to meet criterion of the Eq. (4) in order to keep the power system reliable, instead of only presenting how the reliability evolves according to the share of RES in the energy mix.

Owing to the absence of moving mass in the PV, or to the presence of power electronics in wind plants preventing at this stage of maturity any electromechanical linkage with the power system, the VREs are assumed, in this study, not to participate in the system services. Due to a lack of studies on how interconnections through imports impact kinetic energy, this is considered non-existent in our case. However, it should be assessed according to the mix of the energy imports (renewable origin or not) in order to have a better outlook on the French power sector through reliability arbitration.

We have set four scenarios of renewable energy penetration up to 2050 (Table 1). According to the French energy transition law [40], we constrained nuclear power production at $50 \%$ of 
overall production from 2025 onward with RES penetration objectives of $27 \%$ and $40 \%$ respectively at 2020 and 2030. The RES penetration objectives (shares of power production) in 2050 defined in this table are ambitious targets as a basis of comparison in the analyses of the implementation of reliability constraint.

Table 1: Description of the scenarios

\begin{tabular}{ccccccc}
\hline Scenarios & Years & BAU & $\begin{array}{c}\text { 40EnR } \\
\mathbf{2 0 5 0}\end{array}$ & $\begin{array}{c}\text { 60EnR } \\
\mathbf{2 0 5 0}\end{array}$ & $\begin{array}{c}\mathbf{8 0 E n R} \\
\mathbf{2 0 5 0}\end{array}$ & $\begin{array}{c}\text { 100EnR } \\
\mathbf{2 0 5 0}\end{array}$ \\
\hline $\begin{array}{c}\text { Maximum CO } \\
\text { emissions }\end{array}$ & $2013-2050$ & $39 \mathrm{Mt}$ & $39 \mathrm{Mt}$ & $39 \mathrm{Mt}$ & $39 \mathrm{Mt}$ & $39 \mathrm{Mt}$ \\
\hline $\begin{array}{c}\text { Maximum Nuclear } \\
\text { production }\end{array}$ & $2025-2050$ & $\mathrm{NA}$ & $50 \%$ & $50 \%$ & $50 \%$ & $50 \%$ \\
\hline $\begin{array}{c}\text { Minimum RES } \\
\text { penetration } \\
\text { objectives }\end{array}$ & 2020 & $\mathrm{NA}$ & $27 \%$ & $27 \%$ & $27 \%$ & $27 \%$ \\
\hline
\end{tabular}

\section{Results and discussions}

\subsubsection{Evolution of the French power mix up to 2050}

The Fig. 8 (a) shows the evolution of the French power mix from 2013 to 2050 with the reliability constraint for the five considered scenarios. There are no constraints on RES penetration and nuclear production in the BAU scenario as explained previously. Thus, a slight drop in nuclear energy is observed before 2030 and a massive introduction afterwards. This drop in nuclear is due to assumptions on the upper limits of the pace of installation for different technologies, coupled with a decrease in existing nuclear capacities related to lifetime (decommissioning) in order to avoid massive and unrealistic investments over a short period $^{4}$. In this scenario, nuclear remains the main source of power production in France with more than $75 \%$ of overall production. Exports follow nuclear power production reaching more than 200 TWh in 2050 with the new interconnections, while imports are non-existent. With an increase in RES penetration objectives, a shift in power exchanges is observed, exports decline till almost non-existent at 100\% RES penetration in 2050 while imports grow to reach around one quarter of the power mix (around $125 \mathrm{TWh}$ ). The latter contributes more to the national power balance due to the decrease in national production observed with the increase of RES penetration. Nuclear power and, to a lesser extent, fossil fuels, are substituted mainly by wind and solar, which amount to respectively almost $37 \%$ and $16 \%$ of the power mix by 2050 in the 100EnR scenario.

\footnotetext{
${ }^{4}$ A maximum of $1600 \mathrm{MW}$ is considered by 2020 (Flamanville EPR). For the next years, new capacities of nuclear are assumed with an upper limit of 16 GW by 2030 and 24 GW from 2040.
} 
(a)

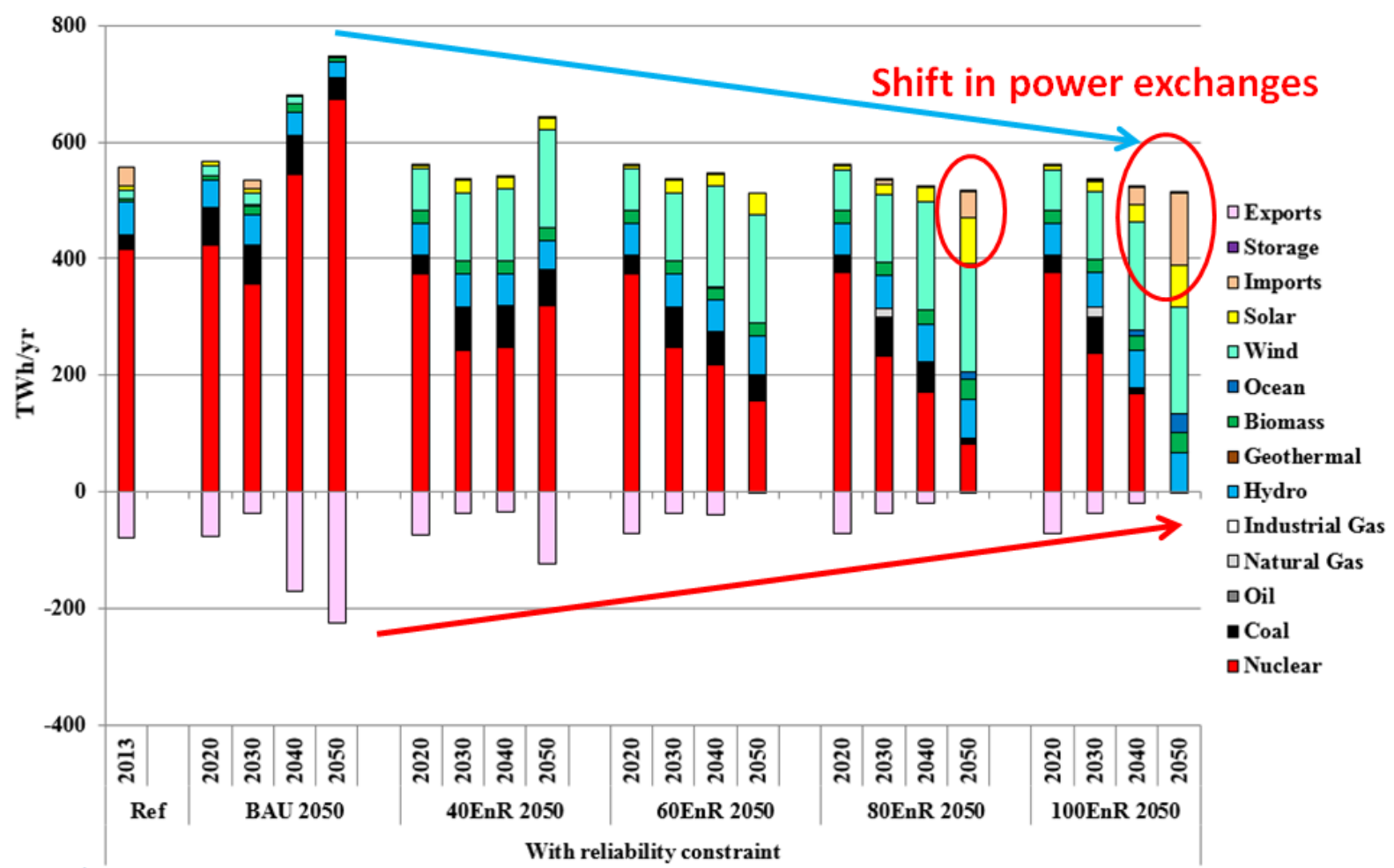

(b)

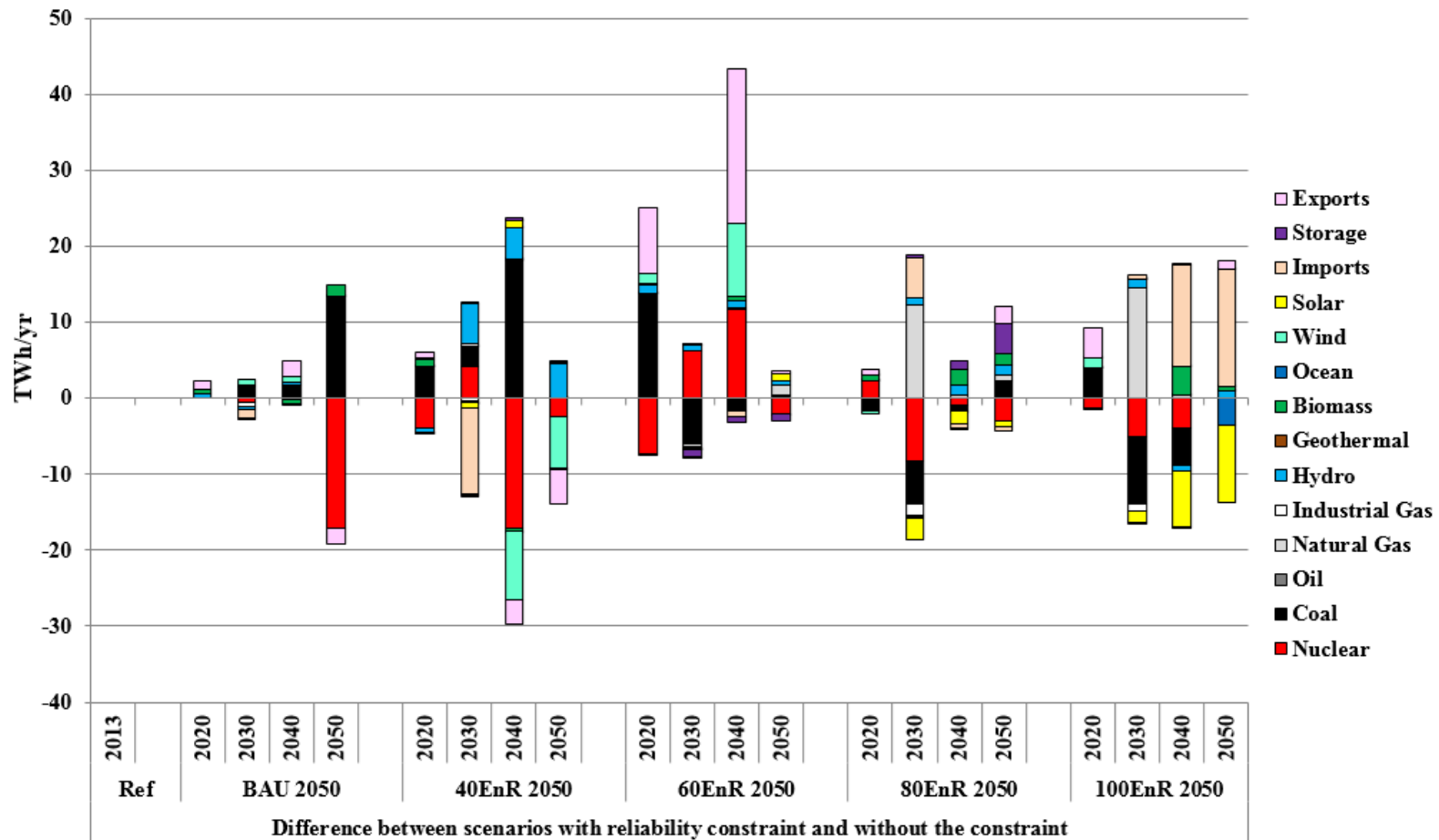

Fig. 8: (a) Evolution of the French power mix for the scenarios with reliability constraint from 2013 to 2050. (b) Difference in the French power mix between the scenarios with reliability constraint (top) and without (bottom) constraint. 
With the endogenous reliability indicator in the model, we observe that it performs an adequate substitution in the power mix (Fig. 8 (b)) in order to comply perfectly with the limit set for the system's reliability constraint (Fig. 9). Indeed, the kinetic indicator has been divided by more than 10 with more RES penetration, to reach 3 seconds in the 100EnR scenario (Fig. 9 (c)), which means that the system has only enough kinetic reserves to face a sudden disturbance during this time (far below the limit of 15-30 seconds before the primary regulation is available).

For example, in the BAU scenario, we observe that between 2020 and 2040 there is a period in which the kinetic indicator falls out of the lower boundary (Fig. 9 (a) below); however with the substitution of imports with fossil productions around 2030 and a massive introduction of nuclear energy in the final years, the kinetic constraint is automatically relaxed, leaving the system with a higher kinetic reserve. Besides, in Fig. 8 (b), a reduction of around 2.5\% of nuclear production can be observed in 2050 in favor of $62 \%$ from coal power plants production and $35 \%$ from biomass production, which could explain a slight decrease in total power production due to a greater efficiency.

In the case of the 40EnR scenario, the reduction of imports in 2030 is replaced by nuclear, coal with CCS and hydro to bring more kinetic reserves to the system (Fig. 8 (b)). Around $6.5 \%$ of nuclear and $6.7 \%$ of wind in power production could be reduced in 2040 to the benefit of $8.5 \%$ more hydro and 33\% more fossil power plants, mainly with carbon capture and storage processes (CCS). The latter correspond to integrated gasification combined cycle power plants (IGCC) using coal as a primary fuel. The reduction of nuclear induces a decrease of $8.7 \%$ in exports. In 2050, nuclear and wind are substituted by hydro and a decrease in exports is observed as before.

In the 60EnR scenario, exports follow nuclear production, as we can see in Fig. 8 (b). This nuclear production allows satisfying the reliability constraint due to a higher wind production by 2040. We note that storage production decreases from 2030 till 2050 with the reliability constraint. This is due to the substitution of advanced adiabatic compressed air energy storage (AA-CAES) with dynamic storage (NAS batteries). Indeed, as mentioned above, these batteries could be used to contribute to the reliability constraint as seen in eq. (1) and in Fig. 11 (b) with an increase of around $200 \mathrm{MW}$ in the storage capacity.

In the $80 \mathrm{EnR}$ scenario, we observe that nuclear is substituted by coal, solar, natural gas and imports early in 2030 (Fig. 8(b)). Moreover, from 2040, more storage and biomass are employed to fulfil the constraints of $80 \%$ renewable energy in power production and system reliability. 
(a)

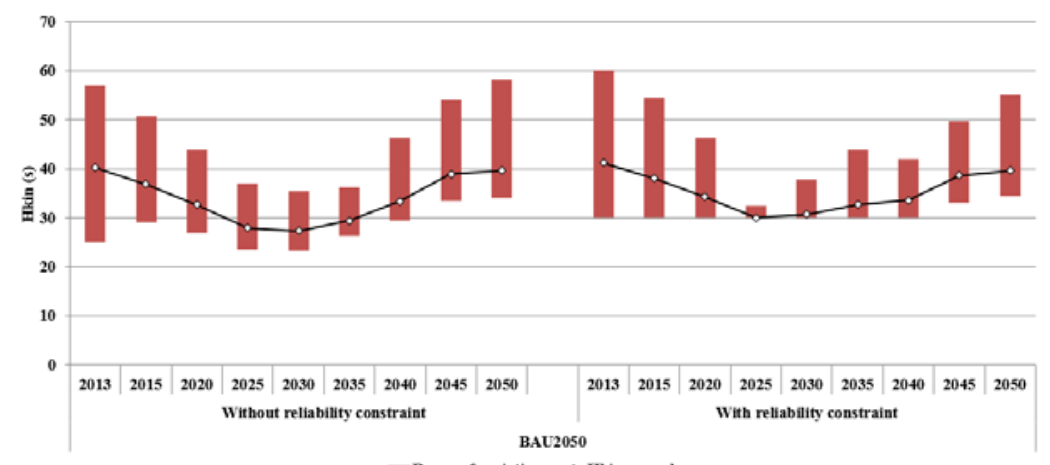

- Range of variation $\cdots$ Hkin annual mean

(b)

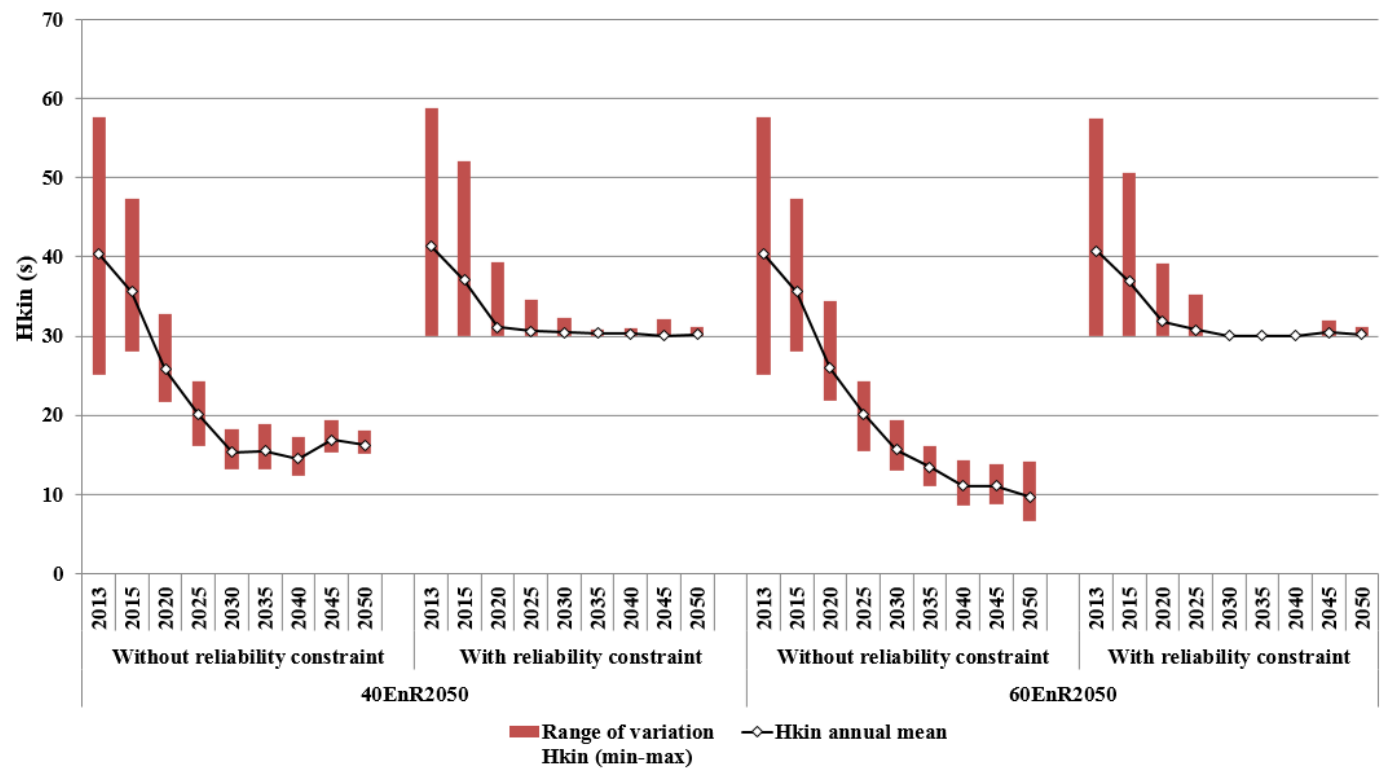

(c)

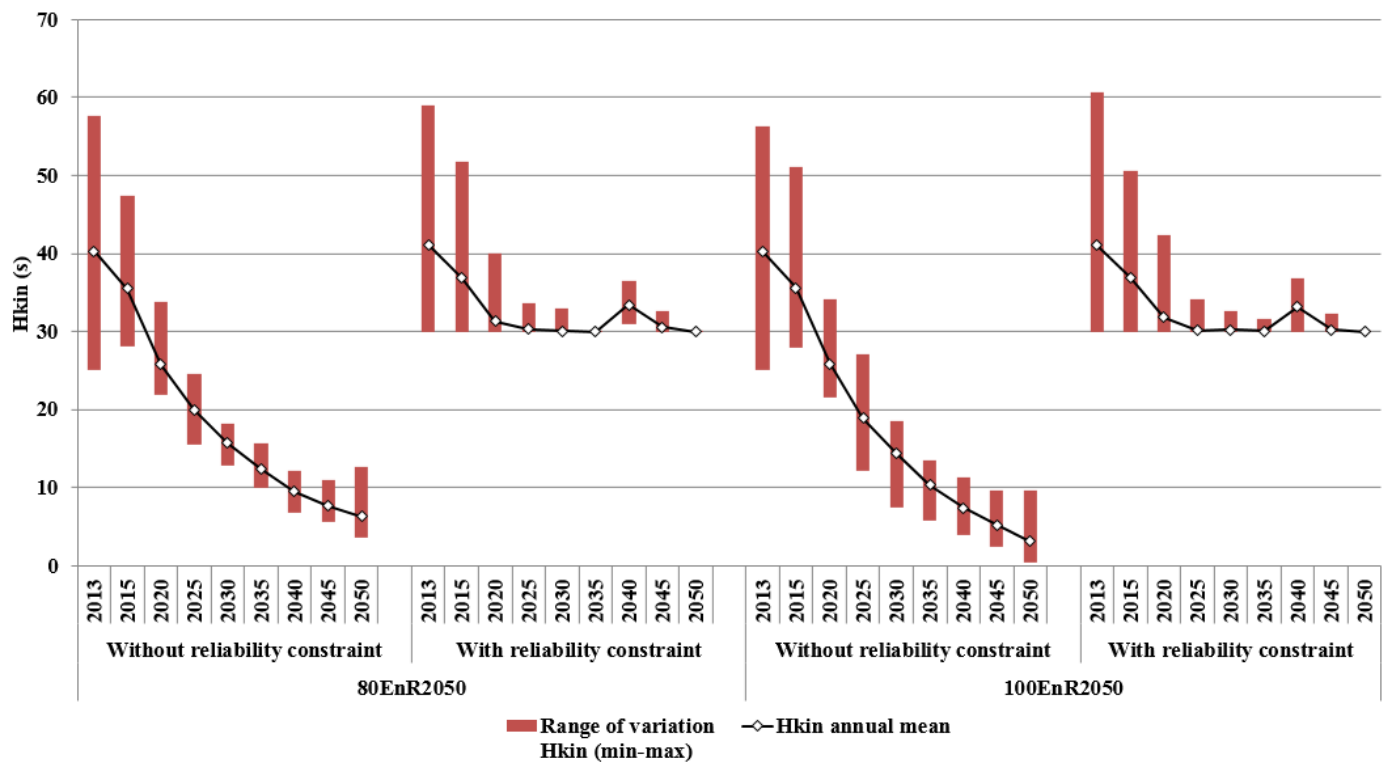

Fig. 9: Evolution of the kinetic indicator $\mathbf{H}_{\text {kin }}$ 
In the 100EnR scenario, the same trend is observed as in the 80EnR scenario, but with fewer imports in early 2030. However, biomass, hydro and more imports (which do not participate in the kinetic reserves but nevertheless compensate the remainder of the demand instead of VRE) are used afterwards, and the emerging of wave power is observed. Biomass and hydro are needed in order to increase the kinetic indicator to its exact limit (Fig. 9 (c)).

As a reminder, imports and VRE do not participate in the kinetic reserves. Achieving a high share of renewables, mainly dominated by VREs, would thus require substitute or additional plants to provide extra inertia to the system. These options might include other means of production or storage devices, or renewable energy technologies (RETs) capable of providing such inertia (see next subsection on installed capacity).

With higher RES penetration by the 2050 horizon, nuclear energy decreases over time in the scenarios (except BAU), combined with more biomass or hydro to achieve the reliability requirement. Wind is expected to be the dominant energy as observed in all scenarios. The system begins to introduce flexible options, such as storage devices and more interconnections (more imports) from the 60EnR penetration, despite the fact that this introduction of storage is quite low, which is more or less visible.

\subsubsection{Evolution of the installed capacity between 2013-2050}

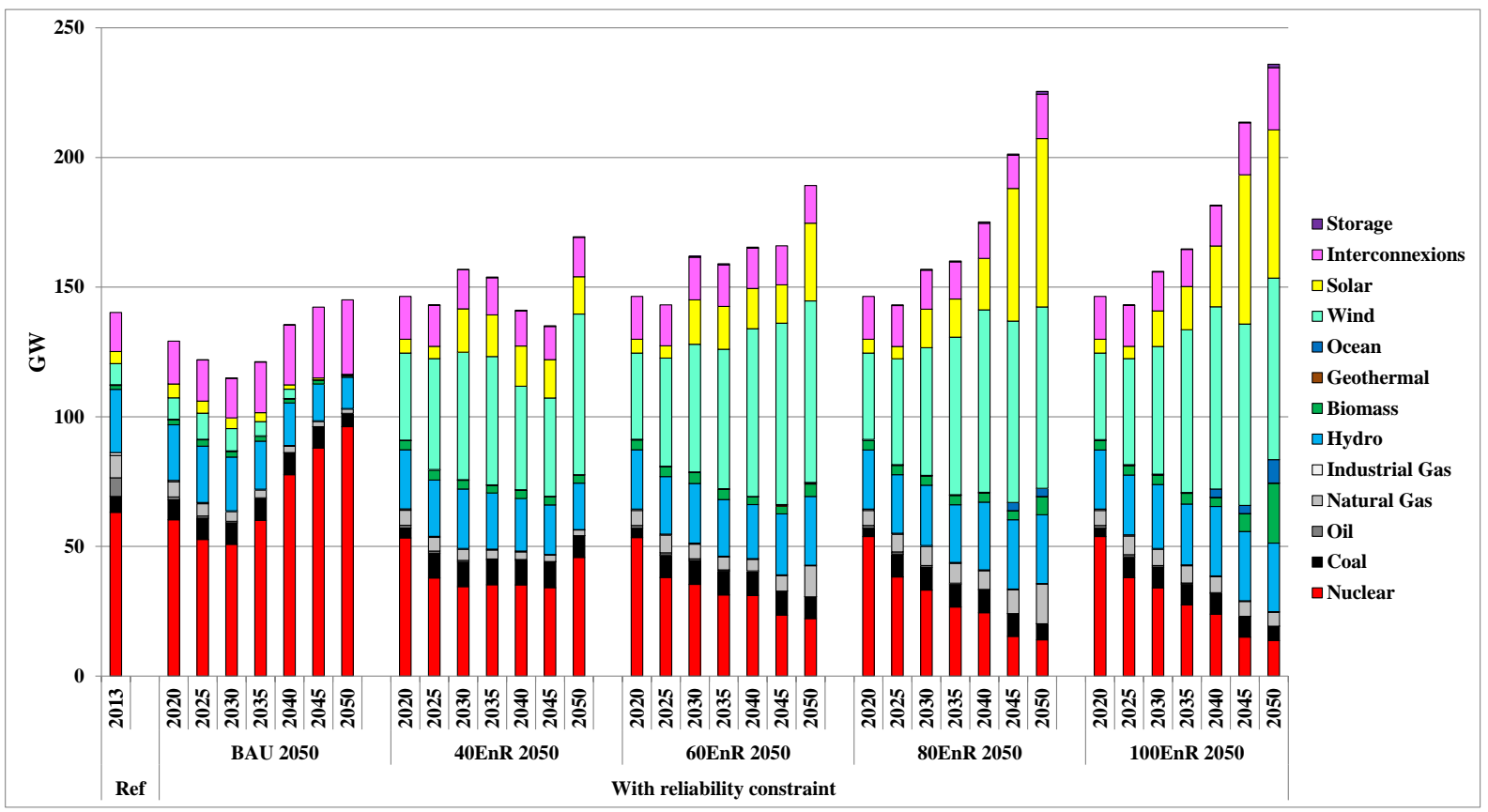

Fig. 10: Evolution of the installed capacity for the scenarios with reliability constraint between 2013-2050 
An increase in the installed capacity is observed in Fig. 10 above for all scenarios and is larger with the RES penetration objectives. The total installed capacity for each technology in a period $t$ is equal to the sum of investments made by the model in past and current periods, and for technologies whose physical life has not yet ended, plus capacity in place prior to the modelling horizon that is still available.

Table 2: RES, interconnections and storage potentials and availability factors considered in this study

\begin{tabular}{|c|c|c|c|c|}
\hline Technology & Potential in 2030 & Potential in $\mathbf{2 0 5 0}$ & $\begin{array}{c}\text { Availability factor / storage } \\
\text { efficiency }\end{array}$ & Lifetime (Years) \\
\hline Imports & $20 \mathrm{GW}$ & $24 \mathrm{GW}$ & $84 \%$ & \\
\hline Exports & $25 \mathrm{GW}$ & $29 \mathrm{GW}$ & $84 \%$ & \\
\hline Onshore wind & $34 \mathrm{GW}$ & $40 \mathrm{GW}$ & $23 \%$ & 20 \\
\hline Offshore wind & $12 \mathrm{GW}$ & $30 \mathrm{GW}$ & $40 \%$ & 20 \\
\hline PV & $33 \mathrm{GW}$ & $65 \mathrm{GW}$ & $14 \%$ & 25 \\
\hline $\begin{array}{l}\text { Hydrokinetic } \\
\text { energy }\end{array}$ & $1 \mathrm{GW}$ & $3 \mathrm{GW}$ & $40 \%$ & 25 \\
\hline Wave energy & $0,2 \mathrm{GW}$ & $10 \mathrm{GW}$ & $40 \%$ & 25 \\
\hline Solid biomass & $13,8 \mathrm{TWh}$ & $15,1 \mathrm{TWh}$ & \multirow{3}{*}{$\begin{array}{l}\text { Depends on technology used to } \\
\text { produce electricity }\end{array}$} & 25 \\
\hline Biogas & 14,3 TWh & $15,1 \mathrm{TWh}$ & & 15 \\
\hline Municipal waste & $12,8 \mathrm{TWh}$ & 13,9 TWh & & 20 \\
\hline $\begin{array}{l}\text { Geothermal } \\
\text { energy }\end{array}$ & $1,2 \mathrm{TWh}$ & 4,6 TWh & $85 \%$ & 20 \\
\hline Hydro & \multicolumn{2}{|c|}{ Current production } & $\begin{array}{l}23 \% \text { for large dams } \\
48 \% \text { for run-of-river }\end{array}$ & $\begin{array}{l}80 \\
70\end{array}$ \\
\hline PHS & $1 \mathrm{GW}$ & $1.5 \mathrm{GW}$ & $45 \% / 75 \%$ & 80 \\
\hline AA-CAES & $0.5 \mathrm{GW}$ & $0.5 \mathrm{GW}$ & $45 \% / 70 \%$ & 35 \\
\hline Other storage & $1 \mathrm{GW}$ & $3 \mathrm{GW}$ & $45 \% / 70 \%$ & 35 \\
\hline
\end{tabular}

This increase is due to the short lifetime of VREs (20 years for wind and 25 for solar) and their availability factors (Table 2), which are lower than those they replaced, and the use of flexible options like biomass plants when VRE production is not able to meet consumption alone. The installed capacity grows by more than $20 \%$ between the BAU and the 40EnR scenario, going from 125 to $155 \mathrm{GW}$ (without interconnections), and a growth of more than two third in the case of the 100EnR scenario to achieve $212 \mathrm{GW}$ compared to the BAU scenario.

This means that in the 40EnR and 100EnR scenarios, a new installation pace, of respectively around 5.7 GW per year or around 7.6 GW per year (for the new installed capacities), is required between 2013-2050 (Fig. 11 (a)) which is huge in comparison with the past French nuclear installation pace of $2.6 \mathrm{GW} / \mathrm{yr}$ (63 GW during 24 years) or the past German wind installation pace of almost 2 GW/yr in around 25 years (50 GW Wind installed in 2016) [41]. The scale of the new capacity installation paces observed in the results, along with an increase in RES penetration objectives, shows that the French power system would require a profound change, but above all else, major upstream planning. 
As we observed above in Fig. 9 with the evolution of the kinetic reserves, we can see in Fig. 11 (b) how the model restrained the decline of the kinetic indicator within these different scenarios. For example, the implementation of the reliability constraint limits the share of VRE in the total share of RES by reducing wind capacity in the 40EnR. Thus, it substitutes around $1.6 \%$ of the nuclear capacity, $1.2 \%$ of the coal capacity, $3.1 \%$ of the wind capacity, and around $10 \%$ of the exports capacity with around $29.7 \%$ more hydro capacity (of which 98\% comes from hydro dams and 2\% from hydro run-of-river) and 130\% more storage capacity (all from dynamic storage to contribute to kinetic reserves).

(a)

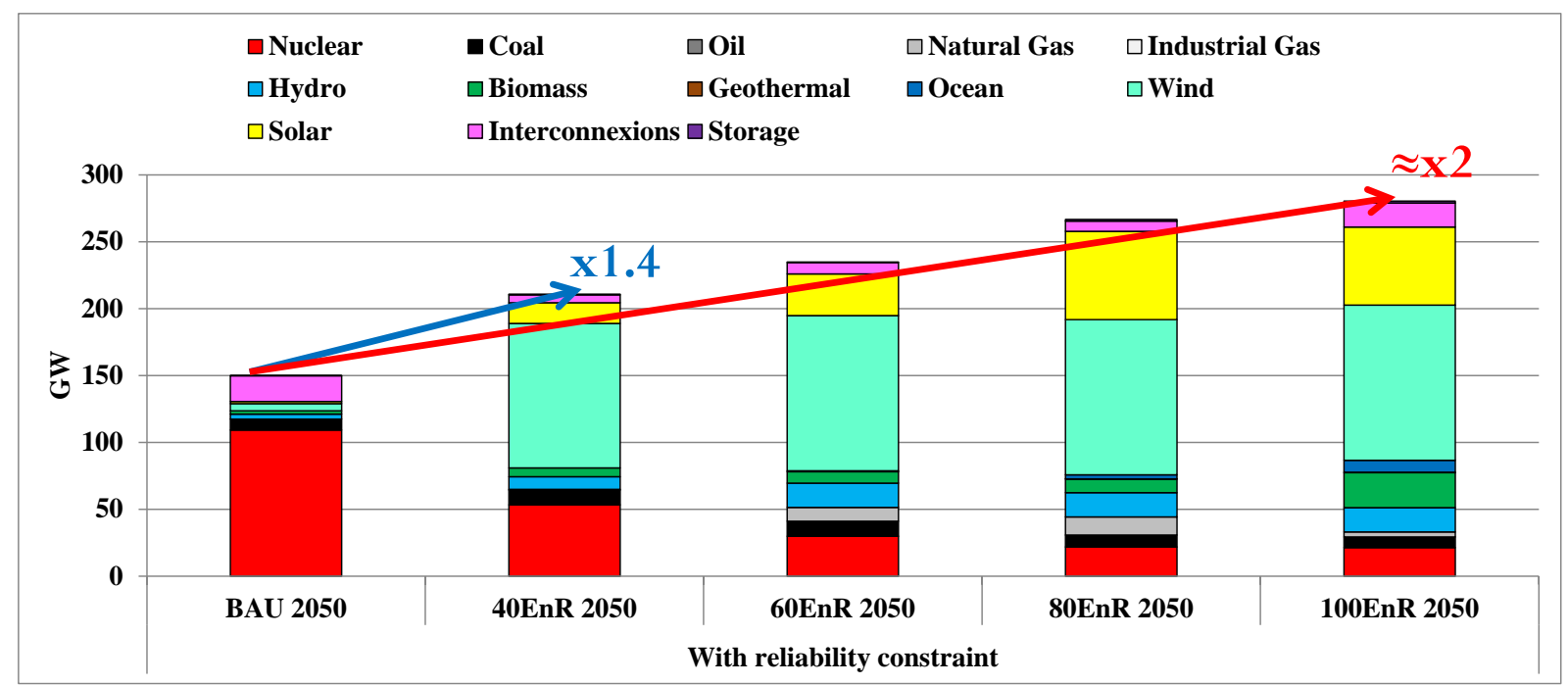

(b)

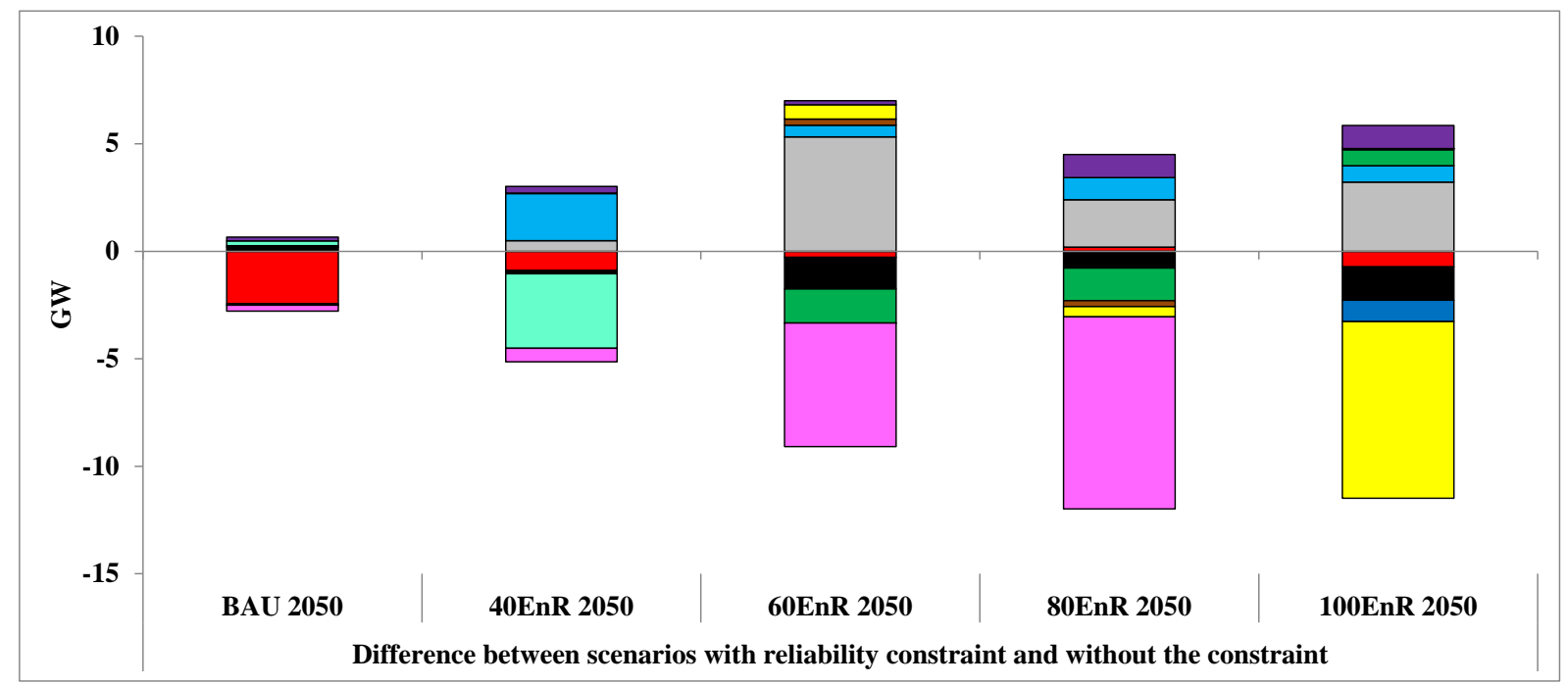


Fig. 11: (a) Evolution of the cumulative new installed capacity for the scenarios with reliability constraint between 2013-2050. (b) Difference in the cumulative new installed capacity between the scenarios with reliability constraint and without the constraint.

In scenarios $60 \mathrm{EnR}$ and $80 \mathrm{EnR}$, we have the introduction of natural gas, hydro and more storage technologies in order to increase the kinetic indicator. The capacity of storage technologies has been multiplied by around eight between the BAU and the 100EnR scenarios, reaching $1.3 \mathrm{GW}$ in 2050. As mentioned above, with the reliability constraint more storage devices are installed. In the 100EnR scenario, the capacity of storage devices is multiplied by around 6 with the reliability constraint, while the capacity of solar is reduced by $12 \%$, coal by $16 \%$ and ocean technologies by $10 \%$ (only wave power capacity which does not participate in kinetic reserves). We note the presence of natural gas in this scenario because this graph (Fig. 11 (b)) is the cumulated new installed capacity, and shows the substitution that occurred between natural gas, nuclear and coal plants between 2025 and 2035 .

In the previous work done by Krakowski et al. [23] where the reliability indicator of the power system had not been considered in the TIMES-FR model, the results obtained for the cumulative new installed capacity between 2013-2050 were around 230 GW, 255 GW, 260 $\mathrm{GW}$ and $310 \mathrm{GW}$ respectively in the 40EnR, 60EnR, 80EnR and 100EnR scenarios. These results are all greater by around $10 \%$ in comparison with our results except for the 80EnR scenario $^{5}$ in Fig. 11 (a) when the power system stability is taken into account. These differences in the results are coming mainly from higher installed capacity of the VREs (Wind and solar) and raise question about the appropriate dimensioning of the energy system in a given region without taking into account the grid reliability. Indeed, Fig. 11(a) gives the evolution of cumulative newly installed capacity according to each scenario between 2013 and 2050 in order to comply perfectly with the limit set for the system's reliability constraint as shown in Fig. 9. This new methodology developed in this article pinpoints clearly the importance of all back-up power plant abovementioned which are necessary for the power system stability and also to avoid power system oversizing (thus the overinvestment) with increasing share of VREs in long-term energy optimization models.

In Fig. 12 (a) we can clearly see how the model limits the VRE's share in the total installed capacity for power production with the implementation of the reliability constraint due to the fact that they do not participate in the kinetic reserves.

\footnotetext{
${ }^{5}$ A decrease by $3 \%$ has been observed between the work without any implementation of the reliability indicator and the result of the Fig. 11 (a). However, if we consider the evolution of the total installed capacity in the same article (115 GW in 2050 in the BAU scenario, $185 \mathrm{GW}$ in the 40\% RES scenario, $224 \mathrm{GW}$ in the $90 \%$ RES scenario and $257 \mathrm{GW}$ in the $100 \%$ RES scenario, the overall cumulated new installed capacity should have been higher for the 80EnR.
} 
(a)

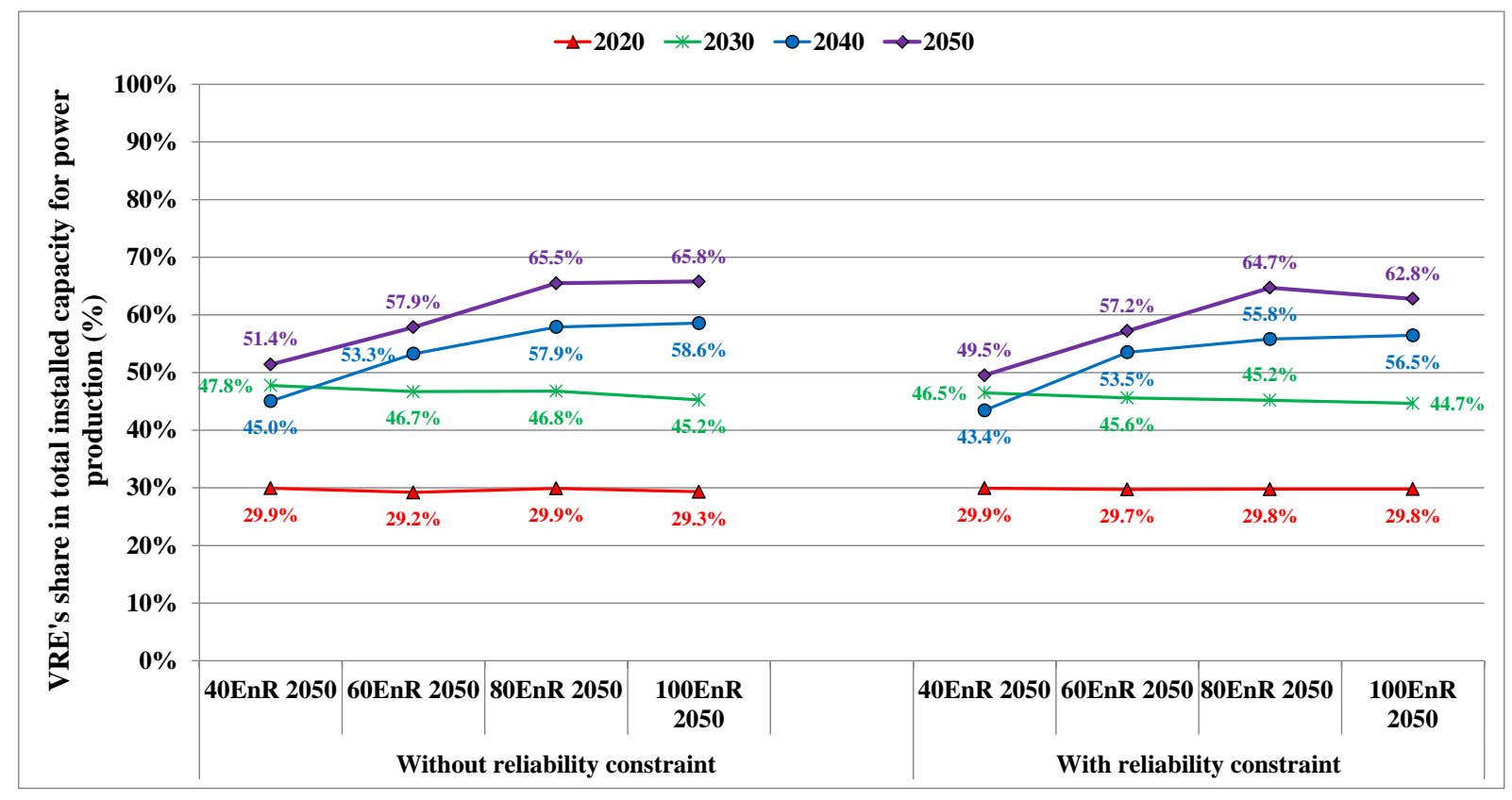

(b)

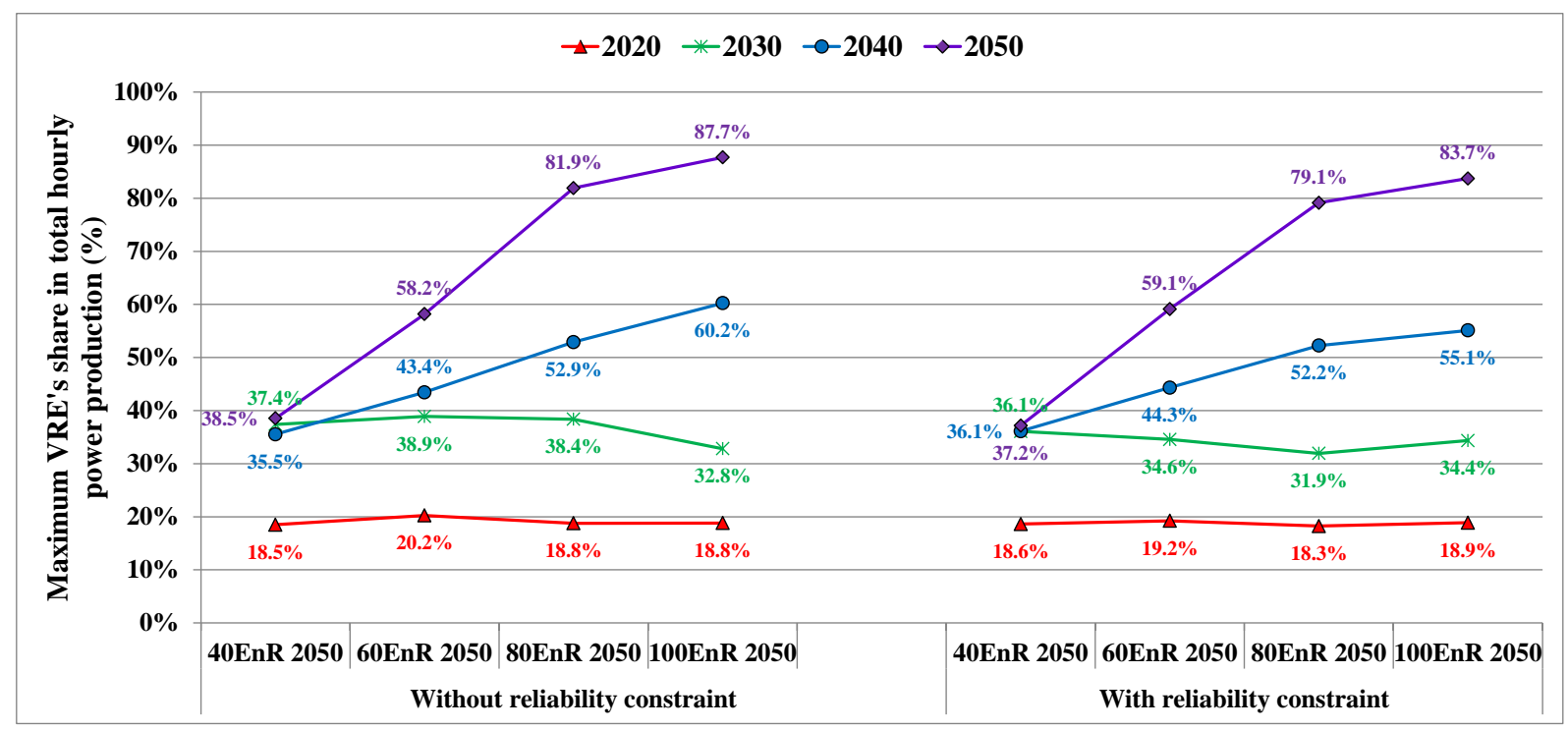

Fig. 12: (a) Evolution of Variable Renewable Energy's share in the total installed capacity for power production; (b) Evolution of maximum Variable Renewable Energy's share in hourly power production observed in a year.

From 2030, comparing the scenarios with and without reliability constraint, the total share of solar, wind and wave power is higher in the second case. This means that we could achieve a maximum of $64.7 \%$ of VREs (wind, solar, wave power) in the total installed capacity by 
2050, obtained with 80EnR and without jeopardizing the reliability of the power system. In the case of $100 \mathrm{EnR}$, no more than $62.8 \%$ is allowed not to be under the limit set for the reliability constraint of 30 seconds of kinetic reserves. In total hourly power production (Fig. 12 (b)), an upward trend without a plateau is observed, unlike the evolution in the installed capacity. The results show that a maximum of $83.7 \%$ of VREs is possible in the hourly power production, observed during the summer between $13 \mathrm{~h}-19 \mathrm{~h}$, when solar production is at its height. This maximum VRE in total hourly power production complies with the reliability constraint as observed earlier in Fig. 9 (c). In addition, we will see in the next subsection that the demand response accounts for around $9.5 \%$ of the hourly power production, reaching around 5.5 GW during the same time slice (Fig. 13). In general, the maximum VRE observed in hourly power production is recorded in the summer during the $13 \mathrm{~h}-19 \mathrm{~h}$ time slot, when demand is lower and the solar production is at its highest.

\subsubsection{Evolution of the hourly power production profile}

As introduced in the previous subsection, the representation of the hourly power production profile is useful to understand the different investments and the role they play according to the scenarios in order to satisfy the reliability constraint. Indeed, we choose to compare three scenarios: 40EnR, $80 \mathrm{EnR}$ and the $100 \mathrm{EnR}$, to observe the modification of power management with high RES scenarios with reliability constraint. We first depict their hourly power production profile up to the year 2050 (Fig. 13) and zoom into different periods of the year 2050, such as summer, winter and the constrained week for a typical weekday comparing 40EnR and 80EnR with reliability constraint (Fig. 14, Fig. 15 and Fig. 16).

In Fig. 13, general observations include an absence of exports and more imports in 80EnR and 100EnR in comparison with 40EnR, where they are non-existent in 2050. We observe less nuclear with more biomass resources and VREs, and the figures clearly depict how the model uses flexible options such as interconnections (imports, exports), demand-response, and storage devices (despite the relatively low introduction of this solution at around $1-2 \%$ of power production, which is not visible) in hourly power production according to the plant production.

In 100EnR (Fig. 13 (c)), biomass power plants are dominant (more than 70\%) during the constrained week (winter period with no imports and the lowest VRE production) and we observe more imports all over the year with the amount of imports almost equalling the power production (around 97.3\%) during the night in summer. Thus, the question of the energy mix in imports and the convergence of energy policies on the European scene would certainly 
arise from an objective of $80 \%$ RES penetration in 2050. Besides, more demand-response is used to postpone around 7.7 GW (around 9.1\%) of night time consumption to the afternoon during summer (negative demand-response) when solar production is highest. Storage capacities are also employed in this scenario, loaded when solar production is greater and delivering power during the night. We see here the need to define demand-response strategies adapted to the power mix. 
(a)

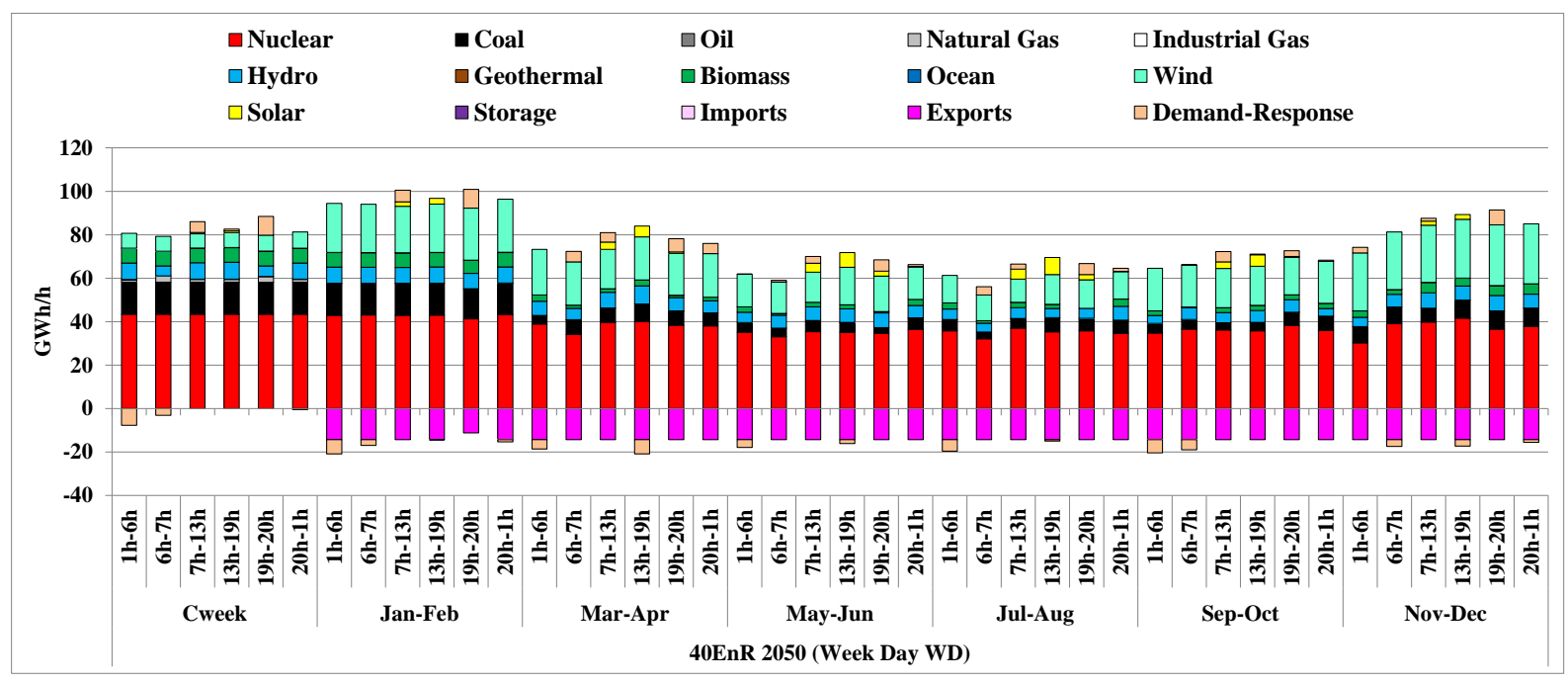

(b)

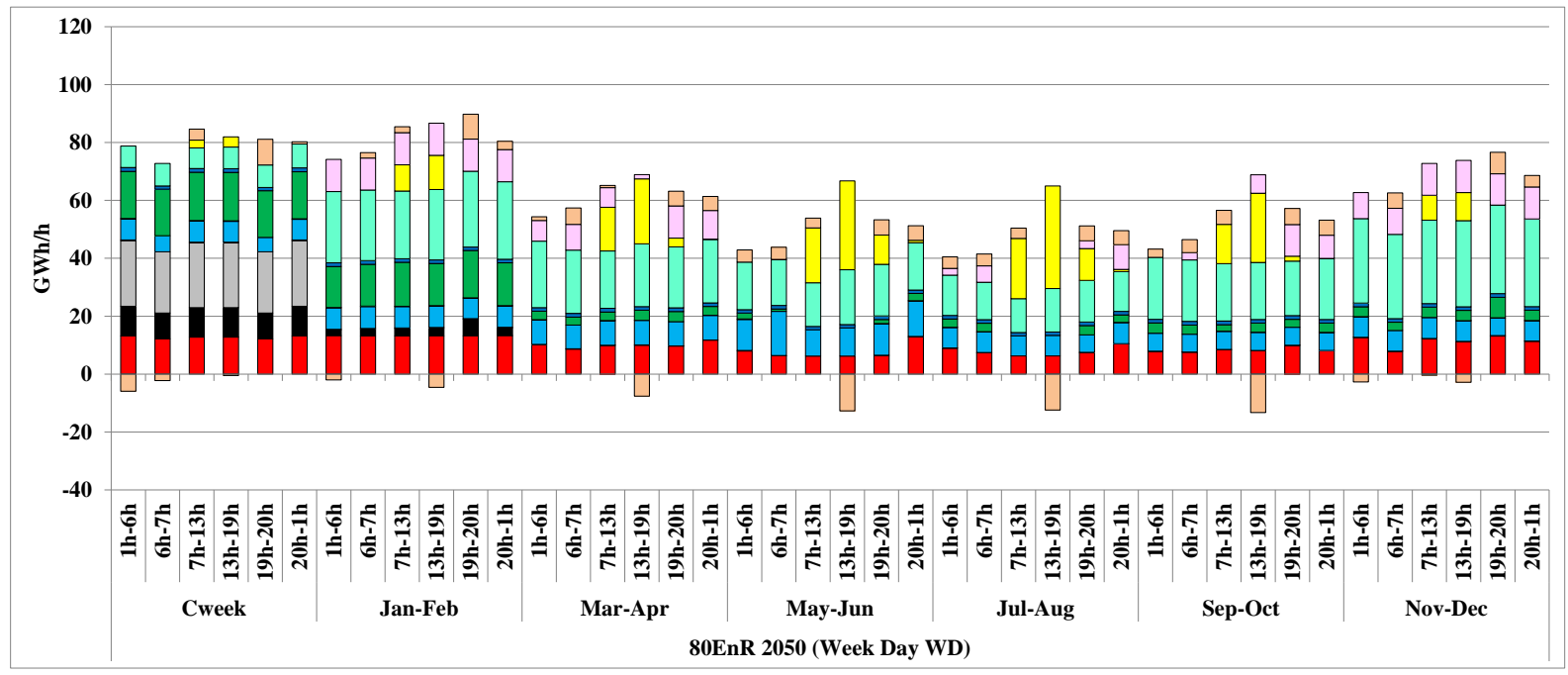

(c)

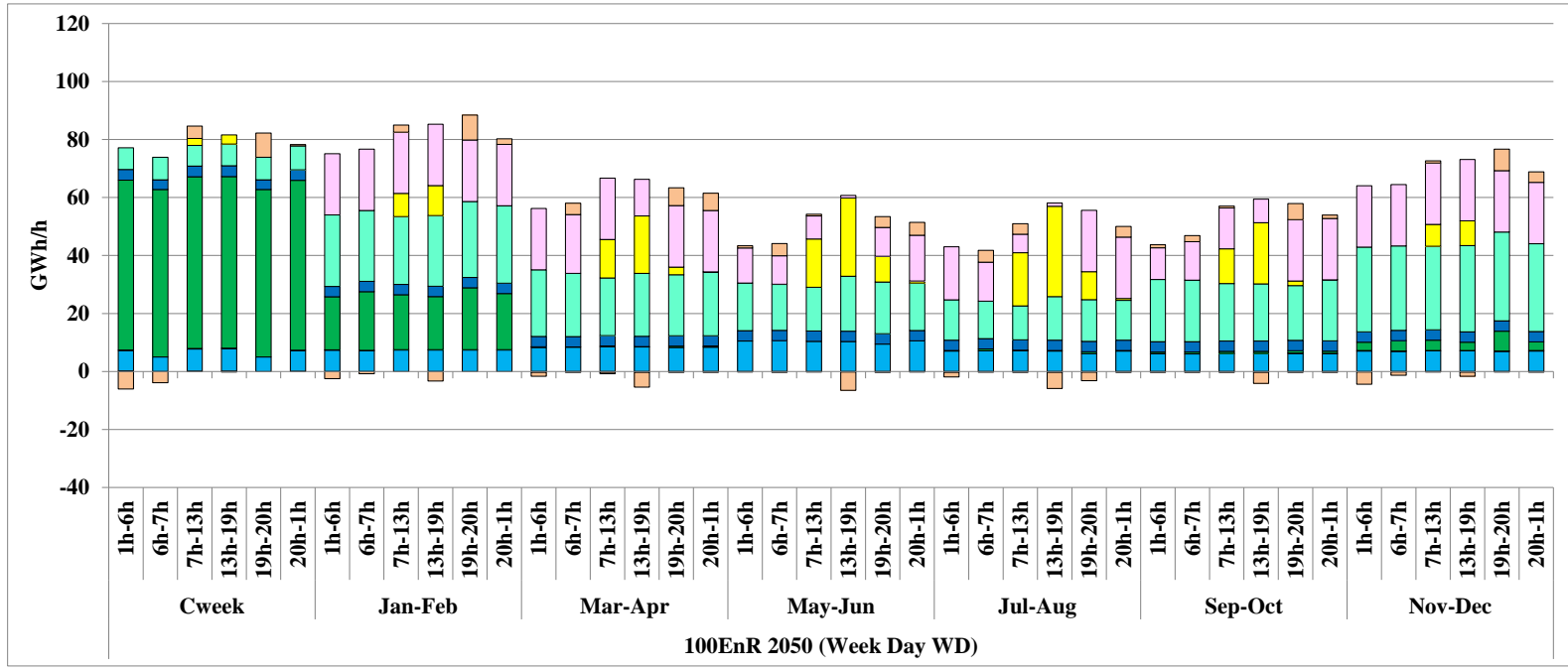


Fig. 13: Comparison for the scenarios 40EnR 2050, 80EnR 2050 and 100EnR 2050 of the hourly power production profile over the year 2050 for a typical week day (WD).

The following Fig. 14, Fig. 15 and Fig. 16 feature a zoom comparison between scenarios 40EnR and 80EnR during a given day (weekday here) respectively in the constrained week, in winter and in summer, in order to observe the detailed levels of the model's potential. During the constrained week in Fig. 14, which is the potential winter with the lowest wind and solar production combined with no imports, biomass and fossil power plants (coal and/or natural gas) are used in order to cover higher demand. In 40EnR, nuclear plants, hydro and a small amount of biomass are enough to maintain the reliability beyond the limit set during this specific period. More biomass resources are used in $80 \mathrm{EnR}$ with natural gas due to the reduction of nuclear, although a saturation of the kinetic indicator is observed as we saw in Fig. 9 (b).

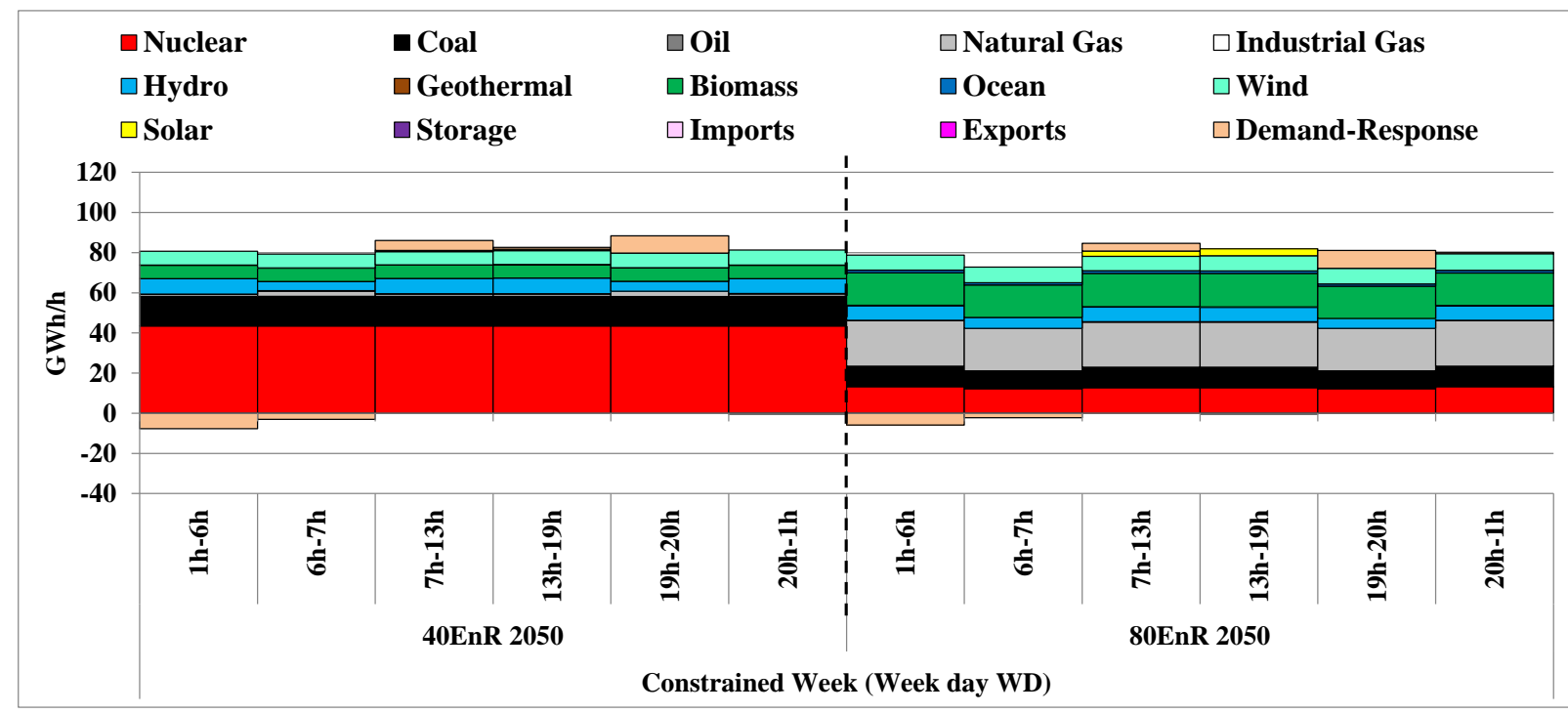

Fig. 14: ZOOM Comparison of the hourly power production profile in 2050 during the constrained week for a typical week day (WD) for scenarios 40EnR 2050 and 80EnR 2050 


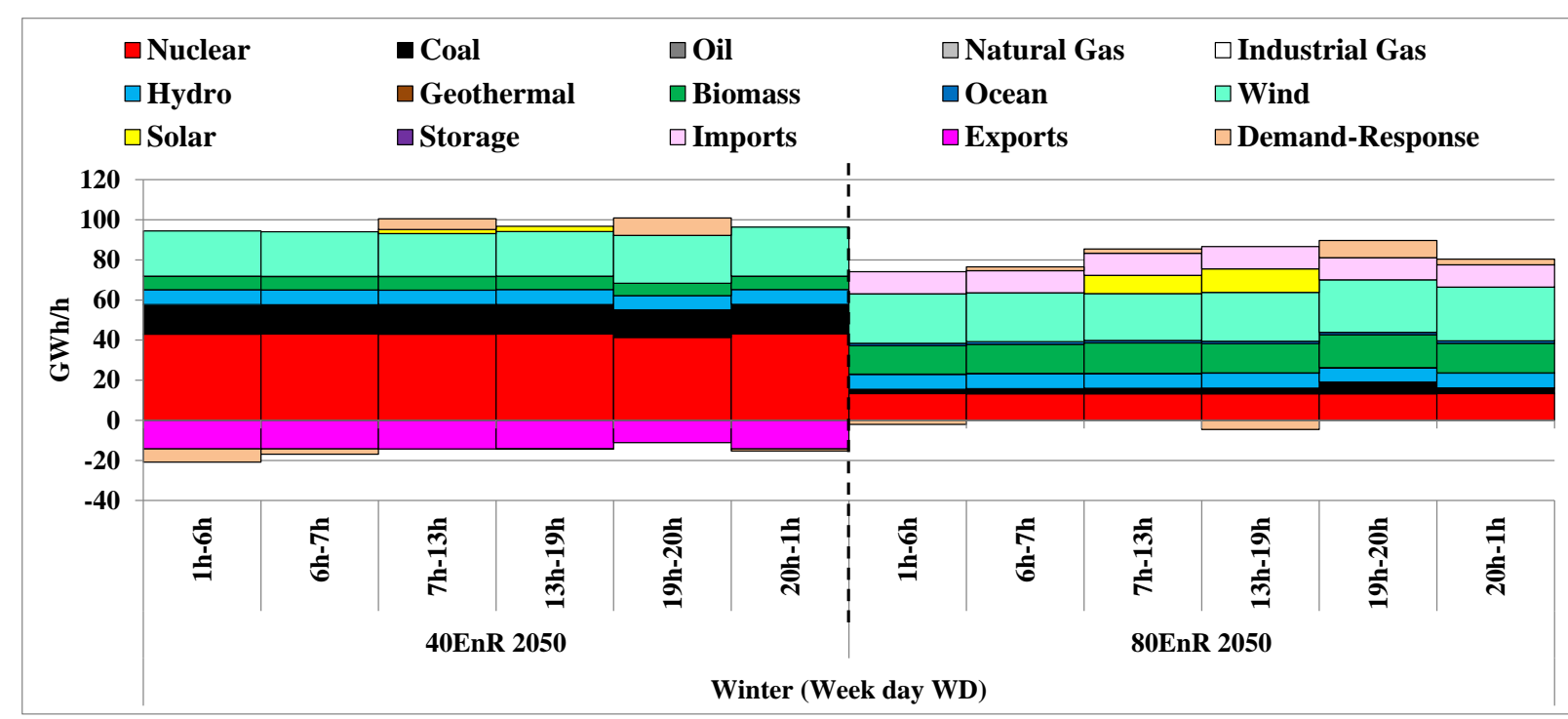

Fig. 15: ZOOM Comparison of the hourly power production profile in 2050 during the winter for a typical week day (WD) for scenarios 40EnR 2050 and 80EnR 2050.

It is interesting to note that biomass is present throughout 2050 in the $80 \mathrm{EnR}$ scenario, while they are only used during the constrained week and in winter in the 40EnR scenario, as seen previously in Fig. 13 (a). In Fig. 15 above, the profile in winter of 40EnR is almost similar to the constrained week, but with exports and more wind. In the case of $80 \mathrm{EnR}$, natural gas and coal have disappeared to be replaced by imports and more wind and solar. During summer, less coal, biomass and wind are observed due to the decrease in demand in Fig. 16. In the case of $80 \mathrm{EnR}$, more solar production and demand-response are obtained during the afternoon, which features the maximum VRE in hourly power production over the year 2050. The demand is postponed during this time slot in order to consume the excess VRE production (mainly solar).

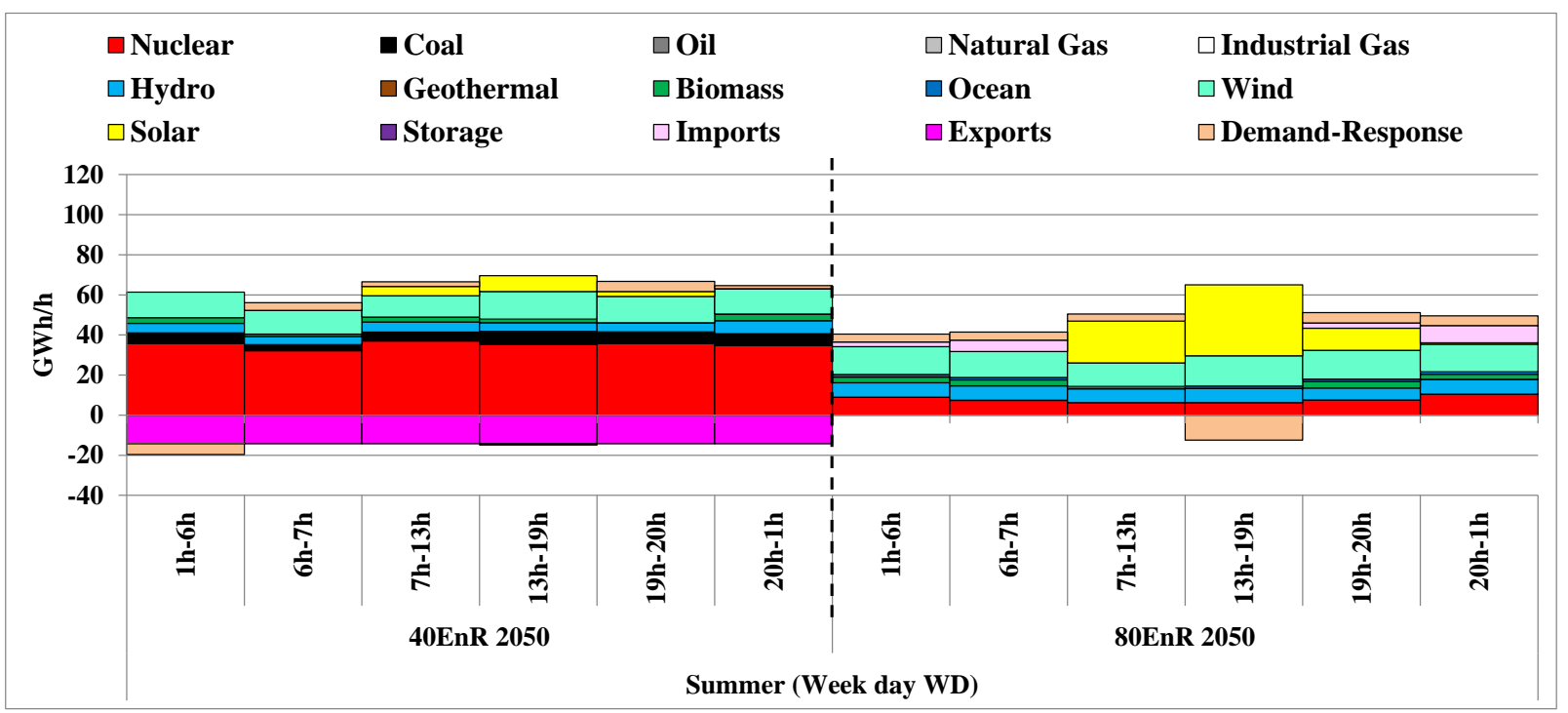

Fig. 16: ZOOM Comparison of the hourly power production profile in 2050 during the summer for a typical week day (WD) for scenarios 40EnR 2050 and 80EnR 2050. 


\section{Conclusions and perspectives}

The results presented so far have allowed us to conclude that high variable renewable energy penetration seems technically feasible without jeopardizing the reliability of the French power system, BUT:

- Achieving a high share of renewables, mainly dominated by VREs, would require a massive installation of new power plants, which increases as penetration objectives become more ambitious. The total cumulative new installed capacity between 2013 and 2050 would double between the BAU and the 100EnR scenarios. This means that a new installation pace of around 5.7 GW per year will be needed only for the 40EnR and around 7.6 GW per year for the 100EnR. These values are very high compared to what has been observed in the past with any type of technology expansion (French nuclear plants, German wind...etc.)

- More flexible options would be required i.e. demand-response, storage technologies and interconnections, or substitute or additional plants to satisfy the reliability constraint at any time by providing extra inertia to the system. Around 55\%, 20\%, $12 \%$ and $13 \%$ of the cumulative flexible option substitution capacity between 2013 and 2050 would come respectively from natural gas, storage (CAES and NaS), biomass and hydro power plants in the 100EnR scenario.

- It also sheds light on the importance of power exchanges with neighbouring countries and therefore the question of their energy mix. With an increase in RES penetration objectives, a shift in power exchanges is observed. Exports decline from $30 \%$ of the total power production by 2050 in the BAU scenario till almost non-existent at 100\% RES penetration while imports is only considered in higher RES penetration to reach around 23\% of the power mix with 123 TWh by 2050 in the 100EnR. It leads to a shift in the trade balance with higher RES penetration.

These results show clearly that ambitious RES penetration would require extra investment. The evolution of the annual cost is depicted in Fig. 17.The imports/exports represent the sum of the electricity costs during power exchanges with neighbouring countries. Here, a negative value means income, which here represents the sale of the electricity in the exports. These incomes are correlated with the share of nuclear in the energy production, which induces more or less electricity exports. 
(a)

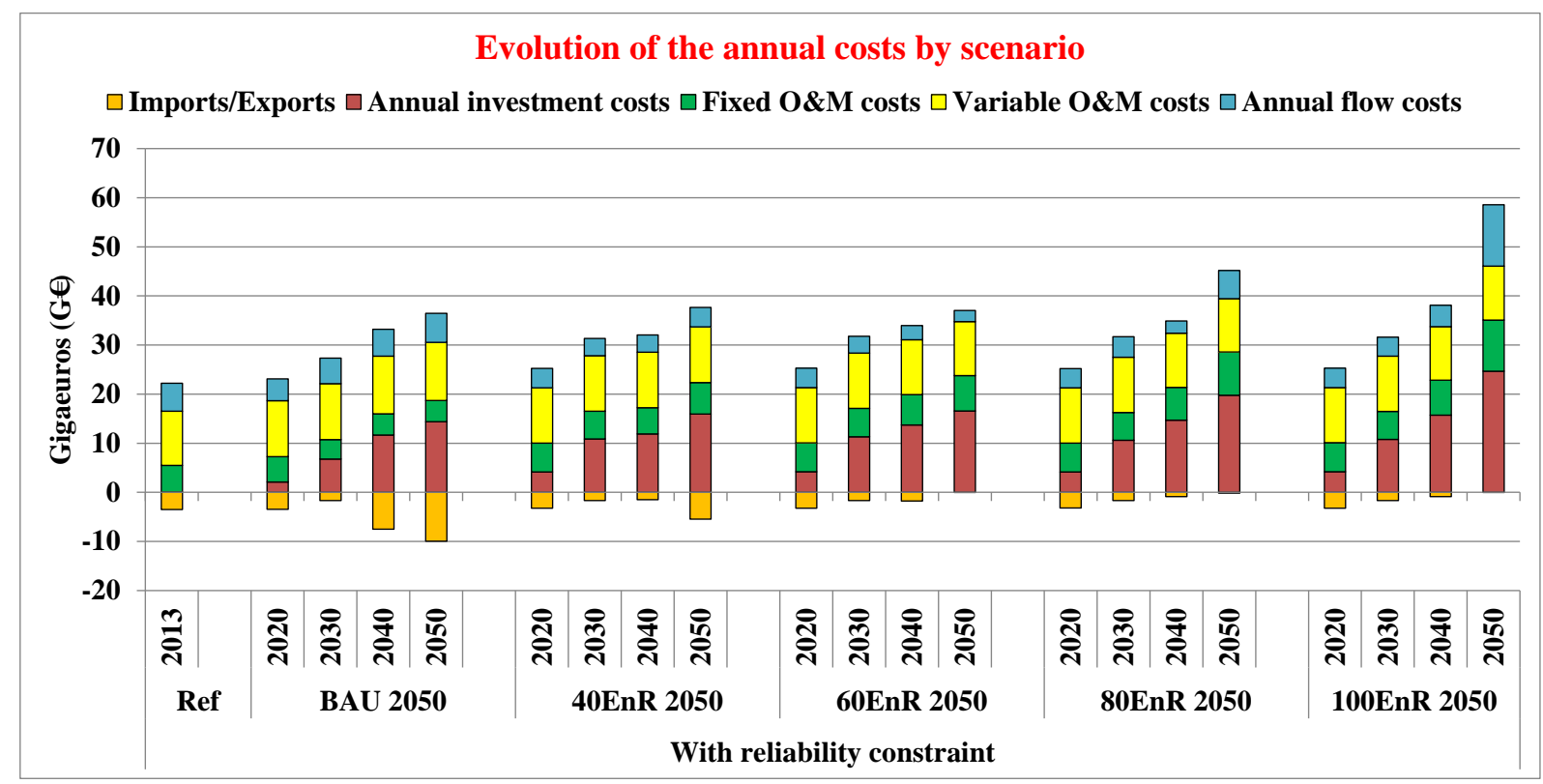

(b)

\section{Cumulated costs by scenario}

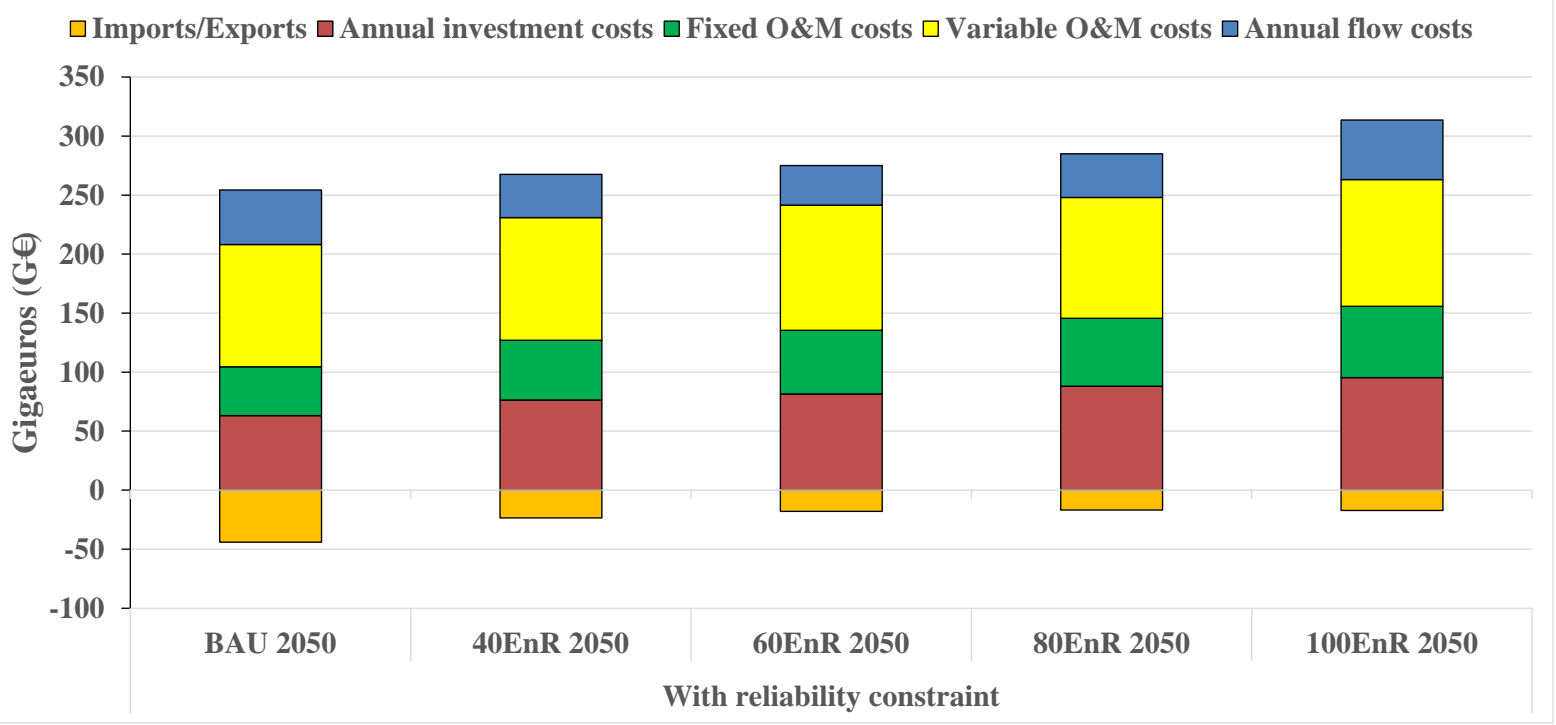

Fig. 17: (a) Evolution of annual costs with RES penetration (b) The cumulated costs with RES penetration during the period 2013-2050. NB: the annual flow costs represent the cost of the fuel consumed, while the annual investment costs, Fixed O\&M costs and Variable O\&M costs constitute the CAPEX (capital expenditure) and the OPEX (operational expenditure)

Thus, as seen previously in Fig. 8, greater income is obtained in the BAU scenario, with around 510 TWh of cumulated exported electricity between 2020 and 2050. This is very far greater than 270 TWh, 150 TWh, 135 TWh and 130 TWh respectively in 40EnR, 60EnR, 80EnR and 100EnR scenarios.

From the BAU scenario to 60EnR, the evolution of investment does not follow RES penetration due to the presence of nuclear. For example, between $40 \mathrm{EnR}$ and $60 \mathrm{EnR}$, the 
substitution of more than half of nuclear with solar (capacity doubled) and natural gas plants (capacity increased fivefold) (Fig. 8) induced a slight decrease in the annual flow costs (sun is free) and almost non-existent incomes from electricity exports.

From scenario 60EnR to $100 \mathrm{EnR}$, the high solar and biomass capacity installed leads to a high increase in investment costs and, following the same trend, in annual flow costs, due to the purchase of biomass and electricity commodities. The shift in the trade balance is clearly observed in the evolution of annual costs where incomes become costs from $80 \%$ RES penetration due to the evolution of the net imports as seen in Fig. 18.

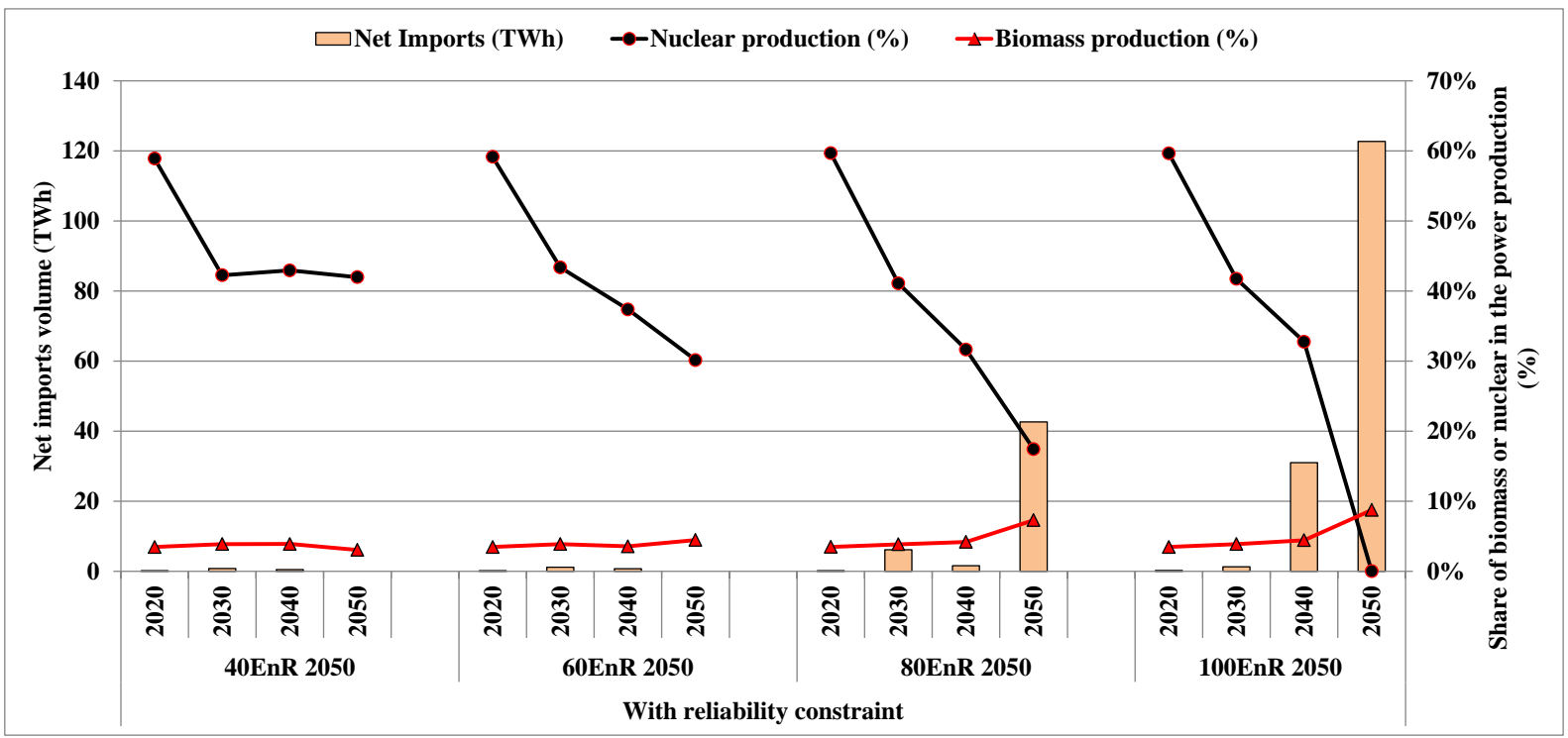

Fig. 18: Evolution of net imports volume (in TWh) and the share of biomass and nuclear in the power production according to RES penetration objectives

Fixed operation and maintenance (O\&M) costs are proportional to the installed capacity; they thus follow the trend of the investment costs. The total installed capacity, which doubles in the 100EnR scenario in comparison with the BAU scenario in 2050, would require a threefold increase in annual costs in order to satisfy the reliability constraint, assuming that synchronism is already acquired.

As a perspective of this research, a posteriori analysis of the synchronism should be done. Indeed, the calculation of the reliability indicator is based on the conservation of synchronism in the power system: without synchronism, kinetic reserves from the different power plants could not be aggregated. In this study, this was ex ante implicitly assumed. Based on the Kuramoto model, which depicts the dynamics of non-linear coupled oscillators connected through a network, the methodology developed in the case of Reunion Island would be the next and final step for the French power system in order to assess the synchronism conditions over the whole power grid. 


\section{Acknowledgements}

This research was supported by SCHNEIDER ELECTRIC and the Modeling for Sustainable Development Chair (MPDD), driven by MINES ParisTech, Ecole des Ponts ParisTech and AgroParisTech, and supported by ADEME, EDF, SCHNEIDER ELECTRIC and GRTgaz.

\section{References}

[1] European Commission, Energy roadmap 2050, 2012

[2] European Commission, 2030 Energy Strategy: A policy framework for climate and energy in the period from 2020 up to 2030, 2014.

[3] Ministère de la Transition Ecologique et Solidaire, Loi de Transition énergétique pour la croissance verte, LOI $\mathrm{n}^{\circ}$ 2015-992 du 17 août 2015, https://www.ecologiquesolidaire.gouv.fr/loi-transition-energetique-croissance-verte

[4] IRENA, Roadmap for a renewable energy future, 2016.

[5] Hache E., Palle A., 2019, Renewable energy source integration into power networks, research trends and policy implications: A bibliometric and research actors survey analysis, Energy Policy 124, pp.23-35

[6] World Commission on Environment and Development (WCED), Our common future, Oxford University Press, 1987.

[7] Renewable Energy Policy Network for the $21^{\text {st }}$ century (REN 21), Renewables 2018 Global status report, 2017.

[8] European Network of Transmission System Operators for Electricity (ENTSO-E), Electricity in Europe in 2016.

[9] Maizi N., Mazauric V., Assoumou E., Bouckaert S., Krakowski V., Li X., Wang P., 2018, Maximizing intermittency in $100 \%$ renewable and reliable power systems: A holistic approach applied to Reunion Island in 2030, Applied Energy 227, pp.332-341

[10]European Network of Transmission System Operators for Electricity (ENTSO-E), 2016, Frequency Stability Evaluation Criteria for the Synchronous Zone of Continental Europe.

[11]Fraisse J-L., Karsenti L., 2014, Raccordement de la production décentralisée aux réseaux de distribution - Conditions d'intégration, Techniques de l'Ingénieur nº D4241 V2

[12] Bloom A., Helman U., Holttinen H., Summers K., Bakke J., Brinkman G., Anthony L., 2017, It's indisputable: five facts about planning and operating modern power systems, IEEE Power Energy Magazine 15, pp. 22-30

[13] Collins S., Deane J.P., Ó Gallachóir B., 2017, Adding value to EU energy policy analysis using a multi-model approach with an EU-28 electricity dispatch model, Energy 130, pp 433-447 
[14] Collins S., Saygin D., Deane J.P., Miketa A., Guttierez L., Ó Gallachóir B., Gielen D., 2018, Planning the European power sector transformation: The REmap modelling framework and its insights, Energy Strategy Reviews 22, pp 147-165

[15] Antenucci A., Crespo del Granado P., Gjorgiev B., Sansavini G., 2019, Can models for long-term decarbonization policies guarantee security of power supply? A perspective from gas and power sector coupling, Energy Strategy Reviews 26, 100410 https://doi.org/10.1016/j.esr.2019.100410

[16] Skar C., Doorman G., Tomasgard A., 2014, The future European power system under a climate policy regime, IEEE International Energy Conference (ENERGYCON), pp. 318325

[17] Skar C., Doorman G., Pérez-Valdés G. A., Tomasgard A., 2016, A multi-horizon stochastic programming model for the European power system, NTNU/CenSES working paper 2/2016, ISBN: 978-82-93198-13-0, 31p

[18] Heylen E., Deconinck G., Van Hertem D., 2018, Review and classification of reliability indicators for power systems with a high share of renewable energy sources, Renewable and Sustainable Energy Reviews 97, pp 554-568

[19] Drouineau M., Assoumou E., Mazauric V., Maïzi N., 2015, Increasing shares of intermittent sources in reunion island: Impacts on the future reliability of power supply, Renewable and Sustainable Energy Reviews 46, pp.120-128.

[20] Drouineau M., “Modélisation prospective et analyse socio-temporelle : intégration de la dynamique du réseau électrique,” Mines ParisTech, 2011.

[21] Drouineau M., Maïzi N., Mazauric V., 2014, Impacts of intermittent sources on the quality of power supply: The key role of reliability indicators, Applied Energy 116, pp333-343.

[22] Maïzi N., Bouckaert S., Mazauric V., Drouineau M., 2012, Procédé d’estimation de la stabilité d'un système électrique

[23] Krakowski V., Assoumou E., Mazauric V., Maïzi N., 2016, Feasible path toward 40$100 \%$ renewable energy shares for power supply in France by 2050: A prospective analysis, Applied Energy 171, pp.501-522.

[24]Krakowski V., Li X., Mazauric V., Maïzi N., 2016, Power system synchronism in planning exercise: From Kuramoto lattice model to kinetic energy aggregation. The 8th International Conference on Applied Energy (ICAE2016), Beijing, China.

[25] Loulou R., Remme U., Kanudia A., Lehtila A., Goldstein G., 2005, Documentation for TIMES model, ETSAP.

[26] Loulou R., Goldstein G., Kanudia A., Lettila A., Remme U., 2016, Documentation for the TIMES model, Energy Technology Systems Analysis Programme. 
[27] Gargiulo M., Getting started with TIMES VEDA, Version 2.7,May 2009, https://ieaetsap.org/index.php/documentation

[28] Remme U., Mäkela J., 2001, TIMES Training Workshop, Gothenburg (Sweden).

[29] Gielen D., Taylor M., 2007, Modeling industrial energy use: the IEAs energy technology perspectives. Energy Economics 29, pp.889-912.

[30] Seck G. S., Guerassimoff G., Maïzi N., 2015, Heat recovery using heat pumps in nonenergy intensive industry: Are Energy Saving Certificates a solution for the food and drink industry in France?. Applied Energy 156, pp.374-389.

[31] Bouckaert S., 2013, Contribution des Smart Grids à la transition énergétique: évalution dans des scénarios long terme, Mines ParisTech.

[32] Assoumou E., 2006, Modélisation MARKAL pour la planification énergétique longterme dans le contexte français, Mines ParisTech.

[33] Seck G.S., 2012, Prospective modeling of the Non-Energy Intensive Industry for the evaluation of the impact of Energy Demand Management policies by using the model TIMES: Assessment of the potential of Heat Recovery with Heat Pumps systems (HP) in French Food and Drink industry, Mines Paristech.

[34] Lebègue D., Hirtzman P., Baumstark L., 2005, Le prix du temps et la décision publique, révision du taux d’actualisation public, Commissariat Général au Plan.

[35] Ministry of Economics and Finances, Taux d'actualisation public et calcul économique, Diagnostics Prévisions et Analyses Économiques n84, Sept. 2005.

[36] ADEME, “L'exercice de prospective de l'ADEME 'Vision 2030-2050' - document technique,” June 2013.

[37]Bouckaert S., Mazauric V., Maïzi N., 2014, Expanding Renewable Energy by Implementing Demand Response, Energy Procedia 61, pp.1844-1847.

[38]RTE, « Bilan prévisionnel de l’équilibre offre-demande d'électricité - édition 2016 », 2016.

[39]Bouckaert S., Wang P., Mazauric V., Maïzi N., 2014, Expanding renewable energy by implementing Dynamic support through storage technologies, Energy Procedia 61, pp.2000-2003

[40] Ministère de l'écologie, du développement durable et de l'énergie, “Energy transition for Green growth. User guide for the act and its attendant actions,” 04-Nov-2015.

[41] Global Wind Energy Council GWEC, Global wind statistics 2016, 2017. 